\title{
A transição da fecundidade no Brasil ao longo do século XX - uma perspectiva regional ${ }^{*}$
}

\author{
Guilherme Quaresma Gonçalves * \\ José Alberto Magno de Carvalho*** \\ Laura Lídia Rodríguez Wong ${ }^{\star \star \star *}$ \\ Cássio Maldonado Turra ${ }^{\star \star \star \star \star}$
}

A essência da transição da fecundidade consiste na mudança de um padrão de intensiva reprodução, quando muitas crianças nascem, mas muitas morrem, para uma reversão desse cenário, passando os nascimentos a serem planejados. Grande parte da literatura sobre a transição da fecundidade no Brasil indica que esse processo teria começado na segunda metade da década de 1960, caracterizando a transição brasileira como tardia e rápida. Apesar desse aparente consenso, o objetivo do presente estudo é indicar quando e onde começou a transição da fecundidade no Brasil, reestimando a transição da fecundidade regional do país. Aplica-se a técnica proposta por Frias e Oliveira, nos anos 1990, aos dados dos Censos Demográficos de 1940, 1950 e 1970 a 2010. Os resultados indicam que a transição da fecundidade já vinha em curso, em parte considerável do Brasil, desde o início da década de 1930, mais especificamente no Rio de Janeiro, em São Paulo e no extremo sul do país. Como consequência desse cenário heterogêneo, foram identificadas duas fases da transição da fecundidade. Na primeira, a transição foi lenta, similar ao modelo europeu, sendo precursores as regiões do Rio de Janeiro, São Paulo e o extremo sul. A segunda fase foi muito rápida, em consonância com a transição da fecundidade dos países retardatários no processo.

Palavras-chave: Transição da fecundidade de período. Brasil. Diferenciais regionais de fecundidade.

\footnotetext{
* 0 presente trabalho foi realizado com apoio da Coordenação de Aperfeiçoamento de Pessoal de Nível Superior (Capes), código de financiamento 001. Cassio M. Turra e Laura Wong agradecem o apoio recebido do Conselho Nacional de Desenvolvimento Científico e Tecnológico (CNPq). Este artigo é produto da tese "Tendência regionais da transição da fecundidade brasileira corrente e de coorte ao longo do século XX", defendida no Programa de Pós-Graduação em Demografia. Agradecemos a Eduardo Rios-Neto, Susana Cavenaghi, Gabriel Borges, Bernardo Queiroz, Carl Schmertmann, além de dois pareceristas anônimos, pelos comentários recebidos em versões anteriores desse trabalho.

${ }^{* *}$ Centro de Desenvolvimento e Planejamento Regional (Cedeplar), Universidade Federal de Minas Gerais (UFMG), Belo Horizonte-MG, Brasil (gquaresma@cedeplar.ufmg.br; https://orcid.org/0000-0002-0507-9956).

${ }^{\star \star \star}$ Centro de Desenvolvimento e Planejamento Regional (Cedeplar), Universidade Federal de Minas Gerais (UFMG), Belo Horizonte-MG, Brasil (carvalho@cedeplar.ufmg.br; https://orcid.org/0000-0002-2303-1892).

**** Centro de Desenvolvimento e Planejamento Regional (Cedeplar), Universidade Federal de Minas Gerais (UFMG), Belo Horizonte-MG, Brasil (lwong@cedeplar.ufmg.br; https://orcid.org/0000-0002-4041-1985).

***** Centro de Desenvolvimento e Planejamento Regional (Cedeplar), Universidade Federal de Minas Gerais (UFMG), Belo Horizonte-MG, Brasil (turra@cedeplar.ufmg.br; https://orcid.org/0000-0003-4051-3567).
} 


\section{Introdução}

A transição demográfica (TD) é definida usualmente na literatura como a mudança de altas taxas vitais, natalidade e mortalidade, para taxas mais baixas. Portanto, a queda da fecundidade é parte desse amplo processo.

Uma característica importante da transição de fecundidade, tal como originalmente conhecida e registrada, é que ela não ocorre homogeneamente no tempo e/ou no espaço. Historicamente, ela começou, em geral, nas zonas urbanas das regiões mais desenvolvidas. Nestas, foram as mulheres mais escolarizadas e com idade mais avançada, dentro do período reprodutivo, que iniciaram o controle deliberado do número de nascimentos, afetando a composição dos filhos em relação à ordem de parturição (KIRK, 1996; KNODEL; VAN DE WALLE, 1979; NOTESTEIN, 1953). Em outras palavras, a proporção de filhos de ordens menos elevadas aumentou entre as mulheres em idade reprodutiva.

Este processo pode também ser identificado nas populações que iniciam a transição da fecundidade após as regiões pioneiras, como no Brasil (ALVES, 1994; CARVALHO; PAIVA; SAWYER, 1981; CARVALHO; WONG, 1992; FERNANDEZ; CARVALHO, 1986; GENDELL, 1967; MARTINE, 1996; ROSEN; SIMMONS, 1971; WONG, 1983a, 1983b; WONG; OLIVEIRA, 1984).

Até os dias atuais há um relativamente generalizado consenso sobre o início da transição da fecundidade brasileira: ela teria se iniciado, dependendo da região, apenas em meados da década de 1960 e durante a de 1970. Esse consenso só foi alcançado no decorrer dos anos 1980, quando as PNADs do final da década de 1970 foram mais bem exploradas e indicaram o início do declínio.

Apesar de claros indícios de queda em algumas regiões, sugeridos pelos dados do Censo Demográfico de 1970, alguns trabalhos os atribuíram não a uma verdadeira tendência, mas sim a diferenciais de qualidade dos dados entre as regiões (CARVALHO, 1974a, 1974b). Alguns autores apresentaram indícios de que a transição da fecundidade poderia já ter começado ainda nos anos 1940, em parte dos municípios brasileiros (POTTER et al., 2006, 2010), ou, em algumas regiões, até mesmo no decorrer da década de 1930 (FRIAS; CARVALHO, 1992, 1994; FRIAS; OLIVEIRA, 1990, 1991; HORTA; CARVALHO; FRIAS, 2000; MERRICK, 1974; SAUNDERS, 1958).

Neste trabalho, coloca-se em questão o início da transição brasileira. Do ponto de vista regional, há indícios de que a transição já estava em curso há bastante tempo, bem antes da queda sustentada e generalizada a partir do final dos anos 1960, como será discutido no primeiro tópico do trabalho. Este artigo apresenta estimativas que permitem se aproximar mais da resposta à seguinte pergunta: quando e onde começou a transição da fecundidade no Brasil? Para tal, considerou-se a transição regional e não apenas a tendência para o país como um todo. 0 principal desafio aqui encontrado, o que justifica, em parte, as escolhas metodológicas adotadas, é a dificuldade em se estimarem taxas de fecundidade total de período (TFT ${ }^{\mathrm{P}}$ ) de maneira direta, pois os quesitos necessários para isso só foram incluídos no Censo Demográfico do Brasil a partir de 1970. 
0 estudo, de caráter empírico, aqui realizado almeja apontar quando o processo da transição da fecundidade teria começado no Brasil, do ponto de vista regional, preenchendo, em parte, o que se considera uma lacuna específica da literatura, além de se gerarem estimativas para desagregações regionais a partir dos anos 1930.

Certamente, o artigo não esgota o tema. Dado o seu caráter estritamente empírico, compreender os diferentes processos e suas nuances é parte de trabalhos futuros que devem ser realizados. Acredita-se que o resgate da discussão sobre o passado traz relevância, uma vez que contribui para entender a atualidade e elaborar melhores prognósticos sobre o futuro.

\section{Do onde ao quando da queda da fecundidade no Brasil: diferentes momentos e ritmos}

0 controle da fecundidade começou entre as mulheres mais escolarizadas e de classes econômicas mais privilegiadas, que teriam sido as pioneiras no planejamento do número de filhos tidos ao longo do seu ciclo de vida. Essas mulheres residiam nas zonas urbanas do Sudeste do país, ou seja, nas áreas mais desenvolvidas na época (ALVES, 1994; CARVALHO; PAIVA; SAWYER, 1981; CARVALHO; WONG, 1992; FERNANDEZ; CARVALHO, 1986; GENDELL, 1967; MARTINE, 1996; ROSEN; SIMMONS, 1971; WONG, 1983a, 1983b; WONG; OLIVEIRA, 1984). A queda generalizada e sustentada da fecundidade só foi possível quando as mulheres com baixos níveis de renda, que respondiam por boa parte da população brasileira, passaram a ter acesso a alguma forma de planejamento familiar, temporário ou não (OLIVEIRA; SILVA, 1986). Uma política de informação e provisão de serviços de planejamento familiar, dirigida às mulheres de baixa renda, acentua a queda da fecundidade, pois favorece a postergação da união e, também, o adiamento da maternidade (RIOS-NETO, 2005).

É justamente em razão da seletividade do início da transição, atrelada às condições econômicas das mulheres e ao desenvolvimento local, que o Brasil tem experimentado um processo heterogêneo da queda de fecundidade, sobretudo do ponto de vista regional. Essa seletividade refletiu-se em relação tanto ao início quanto ao ritmo do declínio, nas diferentes áreas do país, sendo pioneiras as regiões mais desenvolvidas.

Um conjunto de autores apresenta evidências de a queda da fecundidade ter se iniciado em meados da década de 1930 ou de 1940 nas zonas urbanas das regiões Sul e Sudeste (CARVALHO; WONG, 1992; FARIA, 1989; FRIAS; CARVALHO, 1992, 1994; FRIAS; OLIVEIRA, 1990; MARTINE, 1996; MERRICK, 1974; PAIVA, 1987; POTTER et al., 2010; SCHMERTMANN et al., 2013). Entretanto, enquanto a fecundidade apresentava queda no Sudeste a partir desse período, no Norte e no Nordeste ela teria aumentado até o início da década de 1970 e caído a partir daí de forma sustentada e rápida (FERNANDEZ; CARVALHO, 1986; FRIAS; CARVALHO, 1992, 1994; FRIAS; OLIVEIRA, 1990, 1991; WONG, 1983b, 1983a).

Paralelamente aos diferenciais regionais, haveria, também, diferenciação no comportamento reprodutivo intrarregional, no caso, nas zonas rural e urbana. Em meados da década 
de 1960, enquanto a transição da fecundidade sequer havia começado em parte dos setores urbanos do Norte e Nordeste, nas áreas rurais do Rio de Janeiro e São Paulo a transição já estaria em curso (FERNANDEZ; CARVALHO, 1986; WONG, 1983a). Em conjunto, essas evidências refletem o forte descompasso regional da transição da fecundidade no Brasil.

Dentro desses variados cenários, a região Sul aparece como um importante caso ilustrativo, pois, apesar de apresentar maiores níveis do que o Sudeste até a década de 1960, o ritmo de queda da sua fecundidade tornou-se mais acelerado do que no Sudeste, tanto na zona rural quanto na urbana. Já no final dos anos 1970, o Sul registrou os menores níveis do país na zona rural, além de uma TFT similar às de São Paulo e do Rio de Janeiro, na população urbana (FERNANDEZ; CARVALHO, 1986; WONG, 1983a).

O Gráfico 1 apresenta estimativas de Frias e Oliveira (1991) sobre a TFT para o Brasil e suas cinco macrorregiões, entre 1930 e 1990. A heterogeneidade da transição da fecundidade mencionada é clara nessa ilustração. Os diferenciais de nível não seriam grandes no início dos anos 1930 e teriam se tornado crescentes até a década de 1960.

A transição média para o Brasil apresenta declínio da TFT, já na terceira década do século $X X$. Dada essa tendência, a transição poderia ter começado ainda na segunda década, ou até mesmo no início do século XX. Coloca-se dessa forma porque o declínio da fecundidade não significa, necessariamente, começo da transição da fecundidade, podendo ser apenas uma resposta das taxas a mudanças conjunturais.

\section{GRÁFICO 1}

Estimativas das taxas de fecundidade total de período (TFTP)

Brasil e grandes regiões - 1930-1990

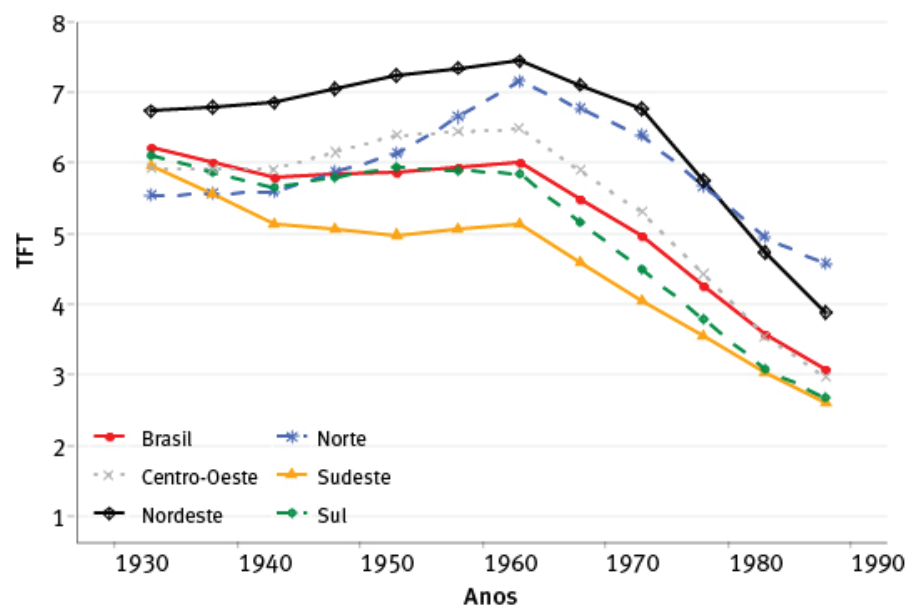

Fonte: Estimativas realizadas por Frias e Oliveira (1991).

Nesse primeiro período de queda da fecundidade brasileira, o ritmo teria sido muito lento, se comparado com a experiência europeia do final do século XIX e início do XX. $O$ declínio teria se concentrado nas macrorregiões Sul e Sudeste, responsáveis em conjunto, em 1920 
e 1940 , respectivamente, por cerca de $56 \%$ e $58 \%$ da população brasileira. Contrastando com este cenário, o Centro-Oeste teria uma fecundidade basicamente constante até o início da década de 1940, ao passo que o Norte e o Nordeste apresentariam níveis crescentes, a um ritmo mais lento nesta última região. Esses diferentes comportamentos e os pesos populacionais muito diferenciados das regiões teriam levado a uma tendência levemente declinante da média nacional.

Provavelmente, mesmo naquelas regiões onde a TFT declinava, a queda teria se concentrado nas áreas urbanas, com graus mais elevados de modernização. Pelo menos desde os anos 1920, as regiões urbanas brasileiras já teriam um menor nível de fecundidade do que as rurais (SAUNDERS, 1958). Essa pressuposição é robusta pelo que se conhece da transição europeia (CLARK, 2007; DYSON, 2010; NOTESTEIN, 1945, 1953) ${ }^{1}$ e pelos diferenciais já citados ao longo dos anos 1960 e 1970, no Brasil (FERNANDEZ; CARVALHO, 1986; WONG, 1983b, 1983a).

Entre os inícios das décadas de 1940 e 1960, teria havido no país uma pequena recuperação do nível médio da fecundidade. Ao se atentar para o que teria ocorrido nas macrorregiões nesse período, observa-se que, naquelas sem indício de declínio da fecundidade até então - Norte, Centro-Oeste e Nordeste -, houve um aumento sensível da TFT, concentrado entre as mulheres de 25 a 34 anos (QUARESMA et al., 2018). De acordo com os dados do Gráfico 1, esse crescimento teria se dado com menor intensidade no Nordeste, enquanto no Sudeste e no Sul teria havido uma estabilização ou uma leve ampliação da TFT. Ponto similar já tinha sido indicado por Simões e Oliveira (1988). A partir de estimativas indiretas das TFT de período, oriundas dos dados dos Censos Demográficos de 1940 a 1980, identificara-se uma leve queda do nível da fecundidade, entre 1940 e 1950, no Sudeste do país. Teria ocorrido uma recuperação entre 1950 e 1960, quando, finalmente, a fecundidade passa a declinar sustentadamente na região (SIMÕES; OLIVEIRA, 1988).

Esse aumento de nível de fecundidade foi também constatado em outros países da América Latina nessa mesma época, como no México (TERÁN, 1990) e na Argentina (SACCO; ANDREOZZI, 2017). Não se sabe o que causou essa tendência de incremento, podendo estar associada a um aumento da fertilidade, consequência de melhorias das condições de nutrição e saúde da população, como teria sido o caso do México (TERÁN, 1990), e também, ainda que marginalmente, a uma diminuição do grau da viuvez das mulheres no período reprodutivo, como consequência da queda da mortalidade masculina adulta. Além disso, outros fatores como qualidade das informações e efeitos tempo na fecundidade não podem ser descartados.

A partir da segunda metade dos anos 1960, inicia-se o segundo período de queda da fecundidade no país. 0 ritmo do declínio foi muito maior do que no primeiro período, atingindo todas as macrorregiões brasileiras rapidamente. Esse curso ocorre em conformidade com o observado em outros países em desenvolvimento, como, por exemplo,

\footnotetext{
${ }^{1}$ Essas são apenas algumas das muitas referências que analisam o início do processo de transição demográfica na Europa, especialmente à luz da teoria de modernização.
} 
no México (TERÁN, 1990; TUIRAN et al., 2002; ZARATE, 1967) e no Irã (ABBASI-SHAVAZI; MCDONALD; HOSSEINI-CHAVOSHI, 2009; LADIER-FOULADI, 1997). O processo tornou-se rápido e irreversível, principalmente a partir da década de 1970.

Essa queda se deu, primeiramente, nas regiões que já vinham experimentando algum tipo de declínio antes dos anos 1950. As demais regiões iniciaram a queda em períodos subsequentes. Nestas, a redução da fecundidade foi mais rápida. 0 Censo Demográfico de 2010 mostrou estar ocorrendo no país uma clara tendência à convergência dos níveis de fecundidade. Essa convergência pode ser observada no nível das macrorregiões, das categorias ocupacionais, bem como entre os diferentes níveis educacionais da população (SACCO; BORGES, 2018).

Uma síntese desses períodos de queda da fecundidade é feita por Rios-Neto (2000). 0 autor aponta que teria havido duas fases de transição de fecundidade no Brasil: a primeira, no início do século XX, com ritmo compatível com a transição europeia, também chamada de "transição clássica"; e a segunda, a partir do fim dos anos 1960, bem mais rápida e intensa (RIOS-NETO, 2000). No presente trabalho, busca-se identificar essas fases, dada a desagregação regional utilizada.

As estimativas apresentadas no Gráfico 1 baseiam-se em estudos publicados a partir de 1991. Na década de 1950 e meados da de 1970, algumas publicações já indicavam o início da queda da fecundidade no Brasil. 0 trabalho de Merrick (1974), por exemplo, aponta que a fecundidade já estaria caindo antes de 1940 em algumas regiões, mais precisamente no Rio de Janeiro (incluindo a Guanabara), em São Paulo e na região Sul. 0 trabalho de Gendell (1967), por sua vez, traz algumas tendências da queda da taxa bruta de natalidade $(T B N)^{2}$ desde o fim do século XIX e início do XX, apesar de concluir que a fecundidade não havia caído ou que pouco tinha variado.

Um problema da baixa variação da TBN, em nível nacional, é que, mesmo que a tendência fosse muito lenta, ou que a transição da fecundidade não tivesse se iniciado no país como um todo, é necessário considerar a variação inter-regional, dada a heterogeneidade da dinâmica demográfica brasileira. Por exemplo, enquanto havia uma correlação positiva entre a fecundidade e a renda no Brasil durante os anos 1940, tendo empregadores uma maior fecundidade do que os empregados, o Rio de Janeiro já apresentava uma relação inversa, o que poderia também ser verdade para outras regiões metropolitanas (SAUNDERS, 1958). Essa relação inversa poderia ser um indício do começo da transição, já que são os grupos mais privilegiados que iniciam o controle deliberado do número de filhos. Por outro lado, a relação inversa no país indicaria que, por mais que o processo tivesse começado, os pesos das regiões pioneiras não eram suficientes para inverter a relação.

\footnotetext{
${ }^{2}$ A comparação da evolução da TBN, evidentemente, está influenciada pela composição etária da população; no entanto, por se tratar de um período em que o processo de mudança do padrão etário não era, ainda, intenso, assumimos que as TBN são, em grande medida, comparáveis. Sua evolução teria se dado na mesma direção da TFT.
} 
Parte do que aqui foi considerada divergência na datação do início do processo teria se dado por alguns fatores, entre eles, questões ideológicas, não se podendo admitir ter o país iniciado a sua transição da fecundidade, sinônimo de modernização, em pleno regime ditatorial militar (CARVALHO; BRITO, 2005). Por outro lado, o próprio Estado não tinha interesse na diminuição do ritmo de crescimento populacional, já que povoar o país, principalmente as regiões vazias, era estratégico do ponto de vista militar, tendo o governo sido contrário ao controle da natalidade e ao próprio planejamento familiar (BERQUÓ, 1987; MARTINE, 1996; MIRÓ, 1987; MUNDIGO, 1987). Essa visão pró-natalista ocorreu do fim do século XIX a meados do XX, quando o controle do número de filhos tidos entrou mais contundentemente no debate público (ROHDEN, 2003).

Quando se tornou insustentável continuar negando a plausibilidade do declínio da fecundidade naquele contexto, diante dos dados das sucessivas PNADs da década de 1970, que indicavam que o processo já se mostrava persistente e intenso, houve uma mudança do foco do debate sobre a fecundidade. Passou-se, então, a discutir e analisar como as desigualdades de acesso aos métodos contraceptivos modernos deveriam ser enfrentadas, uma vez que as mulheres das classes menos favorecidas encontravam-se em enorme desvantagem, em relação àquelas mais privilegiadas (BERQUÓ, 1987; MUNDIGO, 1987). A solução encontrada muitas vezes por essas mulheres era o aborto não seguro, ou, até mesmo, o infanticídio, soluções adotadas desde o início do século XX no Brasil ${ }^{3}$ (ROHDEN, 2003). Dessa forma, e em consonância com o discurso da Conferência do Cairo de $1994,{ }^{4} 0$ controle da prole passou a ser considerado direito sexual reprodutivo da mulher, fugindo da dicotomia controle/não controle.

Além disso, não se deve perder de vista que, até o Censo Demográfico de 1970, os dados e técnicas de estimação disponíveis dificultavam, em muito, a identificação da evolução dos níveis de fecundidade do país. Por exemplo, a técnica P/F de Brass (BRASS; COALE, 1968) só foi desenvolvida na década de 1960 e os quesitos necessários para a estimação da TFT, por meio da técnica, só passaram a estar presentes nos censos do Brasil a partir de 1970. Outras possibilidades, como o método dos filhos próprios (MFP) (CHO, 1971; CHO; RETHERFORD; CHOE, 1986; FEENEY, 1977; GRABILL; CHO, 1965b) ou o modelo relacional de Gompertz (BOOTH, 1980, 1984; MOULTRIE, 2013; ZABA, 1981), só foram desenvolvidas e aprimoradas no decorrer dos anos 1970 e 1980 . A técnica utilizada neste trabalho para a reconstituição da fecundidade, por sua vez, só foi desenvolvida na década de 1990 (FRIAS; OLIVEIRA, 1990, 1991). Ademais, a técnica e as estimativas

\footnotetext{
${ }^{3}$ Para entender como o debate sobre o comportamento reprodutivo se deu no início do século XX, ver "A arte de enganar a natureza: contracepção, aborto e infanticídio no início do século XX” (ROHDEN, 2003).

${ }^{4}$ Foi “na Conferência Internacional de População e Desenvolvimento (CIPD), realizada na cidade do Cairo, em 1994, que [...] as questões relativas à população e desenvolvimento ganharam novos elementos consagrando-se a noção dos direitos sexuais e reprodutivos como direitos inalienáveis das cidadãs e cidadãos de todo o mundo. 0 ambiente pós-Guerra Fria e o ciclo de Conferências Sociais da Organização das Nações Unidas (ONU) ajudaram na criação do Consenso do Cairo. [...] 0 controle da natalidade, enquanto livre decisão da pessoa ou do casal é um direito, mas como uma imposição estatal e como uma ideologia neomalthusiana é uma forma coercitiva de retirar direitos e atribuir à população problemas que não são dela” (ALVES, 2004b, p. 20).
} 
geradas foram pouco exploradas, sendo aplicada e aperfeiçoada somente pelos próprios autores, em parceira com outros pesquisadores (FRIAS; CARVALHO, 1992, 1994; HORTA; CARVALHO; FRIAS, 2000). Os trabalhos que usaram as TFT estimadas por Frias e Oliveira o fizeram para contextualizar diferentes períodos (CAVENAGHI; GOLDANI, 1993; OLIVEIRA; BILAC; MUSZKAT, 2000; PERPÉTUO; WONG, 2006; SIMÃO et al., 2006), ou utilizá-las como insumos para outras estimativas (CARVALHO; HORTA; WAJNMAN, 2000; WAJNMAN, 2012), não havendo investimento, por parte dos pesquisadores, na busca por interpretações que justificassem o possível início da transição da fecundidade, ainda no início dos anos 1930.

\section{Metodologia e dados}

Métodos para a reconstituição de estimativas de fecundidade de período (TFTP)

0 método utilizado para a reconstituição das TFT ${ }^{\mathrm{P}}$, entre os inícios dos anos 1930 e 2000, foi o proposto por Frias e Oliveira (1991). Várias técnicas e métodos, com pressupostos e potencialidades diferentes, não poderiam ser utilizados para essa reconstituição, como, por exemplo, a técnica P/F de Brass, o método dos filhos próprios (MFP) e a história de nascimento $(\mathrm{HN})$, porque os dados disponíveis dos censos anteriores a 1970 impõem fortes limitações para as suas aplicações.

A técnica conhecida como P/F de Brass é utilizada para corrigir o erro de período de referência dos dados de fecundidade corrente declarados em censos e surveys. Esse erro decorre da má qualidade da informação sobre quando as crianças nascidas vivas durante um período recente (geralmente nos últimos 12 meses) teriam nascido. Em países do continente africano, as mulheres tendem a incluir em suas respostas crianças nascidas fora do período de referência (últimos 12 meses) e que, portanto, não deveriam compor a fecundidade da população nos 12 meses anteriores à pesquisa, o que levaria à sobrestimação das TEF e das TFT. É frequente, também, se dar o oposto, como no Censo Demográfico de 1970: a subdeclaração dos nascimentos vivos e, consequentemente, a subestimação dos níveis de fecundidade (BRASS; COALE, 1968).

Para a aplicação da técnica, são necessárias informações do total de filhos nascidos vivos até a data de referência do censo (fecundidade retrospectiva), além do número de filhos tidos nascidos vivos nos últimos 12 meses (corrente). Além disso, umas das condições, segundo os autores, é que a fecundidade seja constante (BRASS; COALE, 1968). Na realidade, para utilizar a razão P2/F2 para corrigir o nível da fecundidade corrente declarada, basta que a fecundidade adolescente (15-19 anos) tenha permanecido constante no quinquênio prévio ao levantamento dos dados (CARVALHO, 1982). No caso brasileiro, ao contrário do acontecido com as mulheres dos demais grupos etários, a fecundidade adolescente cresceu entre 1970 e 2000. Entretanto, como o aumento, apesar de sustentado, não foi acentuado, a subestimação do nível da TFT, em decorrência da queda da fecundidade, seria de apenas cerca de $2 \%$ (MARQUES; CARVALHO, 2018). Opostamente, 
dado o forte declínio, entre os anos 2000 e 2010, a sobrestimação chegaria a quase $10 \%$ (CASTANHEIRA; KOHLER, 2015, 2016), em decorrência da forte queda da fecundidade adolescente (CARVALHO; QUARESMA; SILVA, 2018), identificada, pela primeira vez, no Censo Demográfico do Brasil de 2010 (BERQUÓ; CAVENAGHI, 2004).

A segunda possiblidade mencionada, o MFP (GRABILL; CHO, 1965a), parte do princípio de utilizar os filhos próprios enumerados em um censo ou survey para estimar a função de fecundidade. Por meio da alocação das crianças de 0 a 4 anos às suas respectivas mães e de funções de mortalidade, que permitam suas respectivas retroprojeções, os autores demonstraram que, pela razão criança/mulher, seria possível estimar as TEF e TFT ${ }^{\mathrm{P}}$ médias, referentes ao quinquênio anterior à data de referência da pesquisa. Para tal, são necessárias apenas informações do último quinquênio anterior à pesquisa (GRABILL; CHO, 1965a). Os esforços subsequentes trataram de aplicar esse modelo para horizontes temporais mais longos. Primeiro, para os últimos dez anos (CHO, 1971) e, em seguida, para os últimos 14 anos (CHO; RETHERFORD; CHOE, 1986). Pressupõe-se, neste caso, que até os 14 anos as crianças residam com as suas mães.

Para sua aplicação, necessita-se de uma tabulação dos filhos próprios por idade simples das mulheres, sendo que, para a utilização de dados referentes às crianças de 0-14 anos, são necessárias as informações pertinentes das mulheres de 15 a 64 anos, o que levará a dados não truncados nas idades que correspondem ao extremo do intervalo reprodutivo (15-49 anos), pois as mulheres de 64 anos são aquelas com 49 anos 15 anos atrás (CHO, 1971; FEENEY, 1977). Justamente por isso é que as TFT reconstituídas referem-se aos últimos 14 anos anteriores aos censos ou surveys.

A última estimativa, a HN, é o resultado da reconstituição da história de nascimentos das mulheres que, quando agregadas, possibilita o cálculo das TFT (MIRANDA-RIBEIRO, 2007). A HN é a história de fecundidade de cada uma das mulheres em um período anterior ao censo ou survey. Nela, cada um dos filhos é alocado ao longo do ciclo reprodutivo das mulheres, de forma que se obtém, inclusive, a ordem de parturição dessas mulheres em cada um dos anos anteriores à pesquisa. Quanto maior a acurácia dos dados, maior é a qualidade das estimativas, o que inclui, também, a não seletividade da mortalidade e da migração em relação à fecundidade (BRASS, 1975). Esse tipo de estimativa indireta é altamente relevante, pois não parte da declaração direta dos filhos tidos nascidos vivos, comumente subdeclarados em países em desenvolvimento, como o Brasil (BRASS, 1996; BRASS; COALE, 1968).

Entretanto, como o objetivo deste trabalho é apontar quando e onde se iniciou a transição da fecundidade no Brasil, partindo-se, portanto, de uma reconstituição para anos mais longínquos possíveis, nenhuma das três técnicas seria adequada. No caso do P/F de Brass, os quesitos necessários para a aplicação da técnica só foram incorporados aos censos demográficos do Brasil a partir de 1970. Por sua vez, o MFP, amplamente utilizado por outros estudos que discutiram a transição da fecundidade brasileira (FERNANDEZ; CARVALHO, 1986; MIRANDA-RIBEIRO, 2007, 2006; WONG, 1983a, 1983b; WONG; OLIVEIRA, 
1984), só é possível na aplicação a dados dos censos de 1970 em diante, o que permite a reconstituição até 1956, período este mais recente do que aquele aqui pretendido. Outros trabalhos buscaram utilizar os dados referentes a 1960, disponíveis no IPUMS, estimando TFT até meados da década de 1940 (QUARESMA et al., 2018; VERONA; POTTER, 2008), mas sem muito sucesso. Isso por dois motivos: primeiro, porque não há microdados disponíveis para períodos anteriores ao Censo Demográfico do Brasil de 1960, não sendo possível a alocação dos filhos às mães e, por conseguinte, o insumo necessário para a aplicação da técnica; e, segundo, porque os dados referentes a 1960 são incompletos (POTTER; SCHMERTMANN; CAVENAGHI, 2002). Por fim, a HN padece do mesmo problema do MFP: a necessidade de alocação dos filhos às mães.

\section{O método de Frias e Oliveira (1991)}

Dado o cenário mencionado nos parágrafos anteriores, optou-se pela aplicação da técnica proposta por Frias e Oliveira (1991). A motivação para o surgimento da técnica, inicialmente proposta por Frias e Oliveira (1990), depois revisada e discutida em outros trabalhos (FRIAS; CARVALHO, 1992, 1994; FRIAS; OLIVEIRA, 1991; HORTA; CARVALHO; FRIAS, 2000), foi a falta de informação sobre a fecundidade retrospectiva nos Censos Demográficos de 1950 e 1960. Neles, o quesito sobre filhos tidos englobava tanto os nascidos vivos quanto os nascidos mortos. Os autores propuseram estimar as taxas específicas de fecundidade e a taxa de fecundidade total a partir das estimativas de parturição, obtidas, indiretamente, nesses censos demográficos, após desagregar a informação de filhos tidos em nascidos vivos e nascidos mortos. Com a primeira, segundo eles, seria possível obter, finalmente, os níveis de fecundidade e a sua estrutura, para períodos próximos aos censos demográficos (FRIAS; OLIVEIRA, 1990).

A separação da informação de filhos tidos em nascidos vivos e nascidos mortos dependia exclusivamente de outro insumo: o número de filhos sobreviventes na data de referência do censo. Considerou-se que a função acumulada do número médio de filhos nascidos mortos, por idade da mãe, poderia ser descrita em função do acúmulo do número médio de filhos mortos, por idade da mulher (FRIAS; OLIVEIRA, 1991). ${ }^{5}$ Assim, ressalta-se que, para aplicação da técnica, são necessárias duas informações básicas: o número de filhos tidos pelas mulheres até a idade $x$; e o número de filhos tidos sobreviventes.

Em um cenário em que a parturição declarada não possuísse erro de memória e que a fecundidade fosse constante, a parturição seria igual à fecundidade acumulada até o fim da idade $x$. Por isso, a essência da técnica estabelece uma relação funcional entre a fecundidade acumulada até o fim do grupo etário e a parturição. Se a fecundidade é relativamente estável, ter-se-iam relações em diferentes idades de uma mesma coorte hipotética (FRIAS; OLIVEIRA, 1990), ${ }^{6}$ como segue na equação 1.

$F(a)=G(P(x))$

\footnotetext{
${ }^{5}$ As equações para a estimação dos filhos tidos nascidos mortos estão no Anexo 1.

${ }^{6} 0$ trabalho original de Frias e Oliveira $(1990,1991)$ traz a demonstração da relação funcional.
} 
Onde:

$F(a)=$ fecundidade corrente acumulada até a idade $a$, sendo $a$ igual a $20, \ldots, 50$. $P(x)=$ parturição média, sendo $x$ igual a $17,5, \ldots, 47,5$.

A partir das parturições médias das mulheres de 15 a 19, 20 a 24, 25 a 29 e 30 a 34 anos, além da relação funcional mencionada da equação 1, primeiro, estimam-se as fecundidades acumuladas e, em seguida, desacumulam-se os valores de $F(a)$, obtendo-se, assim, as taxas específicas de fecundidade. As equações utilizadas para esses procedimentos estão no Anexo 1 e os parâmetros necessários para tal encontram-se no Anexo 2 (Tabelas A2 e A3).

As TFT estimadas indiretamente pela técnica não produzem os níveis da fecundidade de período na data exata do censo, mas em algum momento antes da data de referência da pesquisa, em média, sete anos antes. Ou seja, as estimativas são alocadas em torno do meio do segundo quinquênio anterior à data da pesquisa. Como essa alocação foi realizada a partir de dados observados, pode ser que a mudança do padrão de fecundidade afete tal alocação temporal (FRIAS; OLIVEIRA, 1990, 1991).

Dado o intervalo regular entre os censos brasileiros, é possível reconstituir as taxas de dez em dez anos. A exceção seria em 1991. Ao se interpolarem linearmente as TEF entre dois censos, ter-se-iam as TEF e TFT de cinco em cinco anos (FRIAS; CARVALHO, 1992, 1994; FRIAS; OLIVEIRA, 1991). Tal procedimento não foi adotado aqui, pois o pressuposto de que todas as taxas variaram uniformemente ao longo da transição da fecundidade seria muito forte. Por isso, para se obterem taxas intercensitárias interpoladas, aplicou-se o spline cúbico (AHLBERG; NILSON; WALSH, 1967), para cada uma das taxas específicas de fecundidade por idade, diferentemente de Frias e Oliveira (1991) e daqueles que utilizaram tal técnica posteriormente a eles (FRIAS; CARVALHO, 1992, 1994; FRIAS; OLIVEIRA, 1991; HORTA; CARVALHO; FRIAS, 2000), que realizaram uma interpolação linear das TEF.

As estimativas referem-se sempre à fecundidade como um todo, sem discriminação da fecundidade marital, pois nem todos os censos demográficos permitem desagregar a informação segundo mulheres unidas. Outro ponto que merece ressalva é que a informação base para a aplicação da técnica é oriunda da resposta de mulheres sobreviventes. Portanto, diferenciais de mortalidade em relação ao nível de fecundidade das mulheres, especialmente aqueles ligados à mortalidade materna, poderiam afetar as estimativas. Esta limitação está presente tanto na técnica P/F de Brass, quando se pressupõe a não seletividade da mortalidade em relação à fecundidade, quanto na história de nascimentos. Todas as técnicas, sejam diretas ou indiretas, possuem suas condições e pressupostos, não sendo diferente com a proposição de Frias e Oliveira $(1990,1991)$.

Os dados utilizados ao longo do trabalho foram os tomos dos Censos Demográficos do Brasil de 1940 e 1950 e os microdados dos Censos Demográficos de 1970 a 2010, disponibilizados pelo IBGE. Infelizmente, não foi possível utilizar os dados do Censo de 1960, uma vez que os microdados para a região Norte e quatro outros estados foram perdidos, o que corresponde a $25 \%$ do total (POTTER; SCHMERTMANN; CAVENAGHI, 2002). Frias e Oliveira 
(1990) sugerem assumir, como bons, os dados de 1940, 1950, 1970 e 1980 e interpolar os filhos sobreviventes, por idade da mãe, para 1960, a partir de um polinômio do terceiro grau (FRIAS; OLIVEIRA, 1991). Algo similar foi realizado neste trabalho, optando-se por aplicar, mais uma vez, o spline cúbico, para a interpolação do número de filhos sobreviventes (AHLBERG; NILSON; WALSH, 1967) e incluir as informações dos Censos de 1991 a 2010.

Como se busca analisar a transição do ponto de vista regional, dividiram-se os estados em dez grandes regiões. ${ }^{7}$ Os estados do Norte, com exceção do Tocantins, foram agregados em uma única região. Dividiu-se o Nordeste em três (Setentrional, Central e Meridional); o Sul, em duas (Paraná e Extremo Sul) e o Sudeste em três (São Paulo, Rio de Janeiro e Leste). Dada a tabulação dos dados disponível entre 1940 e 1960, manteve-se, no período 1970 a 2010, o Tocantins no Centro-Oeste.

- Amazonas: Rondônia; Acre; Amazonas; Roraima; Pará e Amapá.

- Nordeste Setentrional: Maranhão e Piauí.

- Nordeste Central: Ceará; Rio Grande do Norte; Paraíba; Pernambuco e Alagoas.

- Nordeste Meridional: Bahia e Sergipe.

- Leste: Minas Gerais e Espírito Santo.

- Rio de Janeiro: Guanabara e Rio de Janeiro;

- São Paulo: São Paulo.

- Paraná: Paraná.

- Extremo Sul: Santa Catarina e Rio Grande do Sul.

- Centro-Oeste: Mato Grosso do Sul; Mato Grosso; Goiás; Distrito Federal e Tocantins.

Ao se utilizar essa regionalização, foi possível ampliar a discussão sobre a transição da fecundidade no Brasil, reconstituindo-se as tendências para períodos anteriores àqueles adotados por outros trabalhos que utilizam microrregiões ou municípios. Além disso, as estimativas aqui apresentadas complementam o que já foi mostrado por autores que analisaram macrorregiões. Por exemplo, as reconstituições de Miranda-Ribeiro $(2006,2007)$ se restringem, respectivamente, aos períodos 1956-2000 e 1966-2000. Apesar de Frias e Oliveira (1990) reconstituírem a fecundidade até o início dos anos 1930, isso é feito para Brasil e suas cinco grandes regiões. Portanto, acredita-se que os resultados que se seguem são um avanço por reconstituírem as TFT até o início da década de 1930 para dez grandes regiões, o que evidenciará a heterogeneidade demográfica regional do país e permitirá discutir as diferentes trajetórias da transição da fecundidade nacional, a partir das suas regiões.

\section{Reconstituição dos níveis da fecundidade de período no Brasil: 1930-2005}

0 Gráfico 2 apresenta a reconstituição dos níveis de fecundidade de período entre 1930 e $2005,{ }^{8}$ para o Brasil e suas dez regiões. Quanto mais forte a cor, maior é o valor

\footnotetext{
${ }^{7}$ Esta classificação foi utilizada pelo IBGE na publicação dos dados preliminares do Censo de 1970.

${ }^{8}$ Os valores das taxas apresentadas no Gráfico 2, assim como das TEF estimadas, estão no material suplementar do trabalho, disponivel em: 〈https://github.com/gquaresma89/REBEP_2019〉.
} 
da TFT ${ }^{\mathrm{P}}$. O primeiro ponto que merece destaque é que, ao se dividir o país em dez grandes regiões, uma história mais heterogênea surge. No Brasil, enquanto média ponderada das dez regiões, a TFT ${ }^{\mathrm{P}}$ teria declinado durante os anos 1930. A partir do segundo quinquênio da década de 1940, teria havido uma leve recuperação até o final dos anos 1950 ou início dos 1960, quando, finalmente, o nível da fecundidade de período passou a diminuir de maneira sustentada e rápida.

Apesar da tendência nacional, fica claro, no Gráfico 2, que uma análise baseada apenas na média nacional omite grande parte da heterogeneidade demográfica do país, mencionada no parágrafo anterior. Com relação aos diferenciais de nível, observa-se que o Nordeste Central tinha as maiores TFT no início da década de 1930. Enquanto as mulheres desta região, no final do período reprodutivo, teriam tido, em média, 7 filhos nascidos vivos, no Rio de Janeiro, a TFT era inferior a 5 e, em São Paulo e no Extremo Sul, encontrava-se em torno de 6 filhos por mulher. A Amazônia, por sua vez, no início dos anos 1930, teria apresentado um nível de fecundidade de período inferior a essas regiões, com exceção do Rio de Janeiro e ao Brasil como um todo, tendo sido estimada uma TFT em torno de 5,5. Chama a atenção esse baixo valor para a Amazônia. A região tinha um baixo percentual de mulheres casadas dentro do período reprodutivo, no início das décadas de 1940 e 1950, para as quais há a informação necessária (censos), o que diminuiria o tempo de exposição à fecundidade e poderia ajudar a compreender, ao menos em parte, a baixa fecundidade de período na região, nos anos 1930 (QUARESMA, 2019).

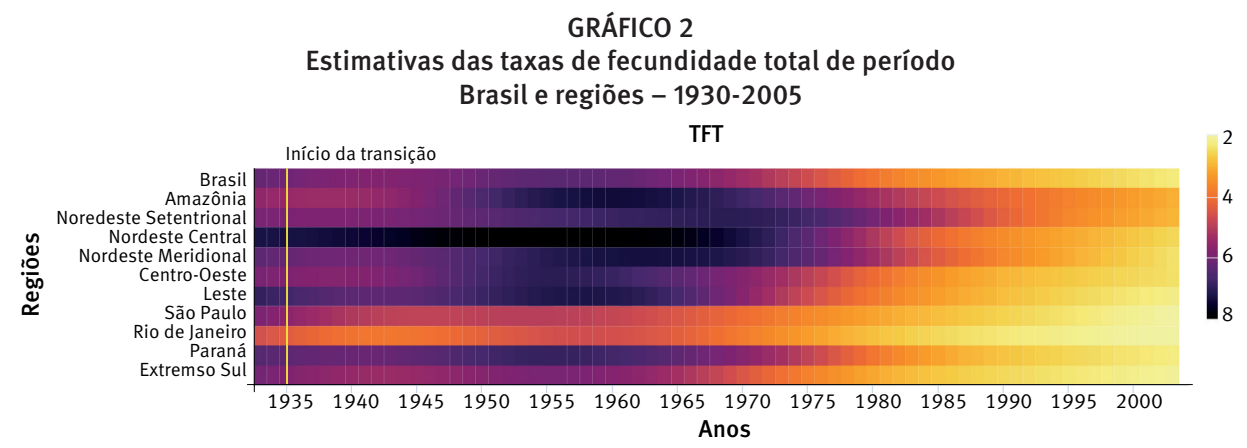

Fonte: Dados básicos dos Censos Demográficos de 1940, 1950, 1970 a 2010.

Nota: Taxas de fecundidade total estimadas a partir da aplicação da técnica proposta por Frias e Oliveira (1991), após breve ajuste na interpolação das taxas quinquenais.

Com a divisão regional aqui utilizada, a queda no início dos anos 1930, apontada por Frias e Oliveira $(1990,1991)$, fica mais evidente. Aparentemente, algumas das dez regiões já apresentavam algum grau de declínio da fecundidade naquele período, com intensidades diferentes. As regiões Leste e Paraná teriam apresentado uma queda mais suave entre o início da década de 1930 e a de 1940. Por outro lado, o Extremo Sul e, principalmente, o Rio de Janeiro e São Paulo mostram indícios mais destacados de queda. 
A recuperação da fecundidade observada na média nacional, entre os anos 1940 e fim da década de 1950, fica mais perceptível em algumas divisões regionais. Aparentemente, ela teria se concentrado nas regiões Amazônia, Leste, Nordeste Meridional, Centro-Oeste, Rio de Janeiro, Paraná e Extremo Sul. Em São Paulo, por sua vez, a fecundidade praticamente teria permanecido constante até o fim dos anos 1950 para, em seguida, começar a declinar sem interrupções. No Nordeste Central e Setentrional, com ritmos diferentes, a TFT teria crescido até o início dos anos 1950, na primeira região, e começo da década de 1960, na segunda, quando, só então, teria começado a cair.

Após o início da década de 1960, a fecundidade começou a declinar paulatinamente por todo o país. 0 início da queda se deu, primeiramente, nas regiões que já vinham experimentando algum declínio até o começo dos anos 1940. Como mostrado no Gráfico 2, parte do Nordeste brasileiro teria experimentado esse fenômeno somente a partir do início da década de 1970. Não por coincidência, todas as regiões pioneiras possuem uma característica em comum: são regiões do Sul e Sudeste do país, as mais desenvolvidas naquele período.

Para se avaliar a qualidade da reconstituição apresentada no Gráfico 2, os dados para 0 Brasil, enquanto média nacional, são comparados às estimativas de outros autores (Gráfico 3). Tal avaliação é importante para este trabalho, já que cada umas das estimativas indiretas parte de pressupostos distintos. 0 mesmo procedimento não foi repetido para todas as dez regiões por dois motivos: parcimônia, já que seria exaustivo apresentar tantos dados; e porque nem todos os autores apresentam estimativas de TFT dessas regiões.

Como se observa no Gráfico 3, as estimativas aqui apresentadas não diferem significativamente dos níveis de fecundidade estimados por outros autores, por meio de técnicas diferentes daquelas aqui aplicadas, com limitações e vieses diferentes. Registra-se uma breve queda da fecundidade, entre meados das décadas de 1930 e 1940, detectada tanto por Carvalho (1974) como, ainda, nas estimativas de Mortara (1954, 1961). A principal diferença entre as TFT dá-se ao longo dos anos 1950. 0 aumento da fecundidade, aqui mencionado, entre meados da década de 1940 e fim da de 1950, é menos acentuado nos resultados de Frias e Oliveira ${ }^{9}$ do que nos dados deste artigo. Entretanto, as estimativas para esse período foram realizadas de maneira diferente. Enquanto Frias e Oliveira estimaram as TEF para os períodos intercensitários de maneira linear, sob o pressuposto de que todas as taxas variaram uniformemente no tempo, aqui utilizou-se a tendência própria de cada uma das taxas, entre 1930 e 2005 , ao se aplicar o spline cúbico. Os dados oficiais do IBGE têm, para esse período, níveis de fecundidade mais próximos aos do presente trabalho do que aqueles de Frias e Oliveira.

\footnotetext{
${ }^{9}$ Em relação às estimativas utilizadas para comparação, vale ressaltar as de Frias e Oliveira. Aquelas aqui apresentadas são derivadas do trabalho original, de 1990, e de suas atualizações posteriores (FRIAS; CARVALHO, 1992, 1994; FRIAS; OLIVEIRA, 1990, 1991; HORTA; CARVALHO; FRIAS, 2000).
} 
GRÁFICO 3

Estimativas das taxas de fecundidade total de período (TFTP), segundo vários autores selecionados Brasil - 1930-2015

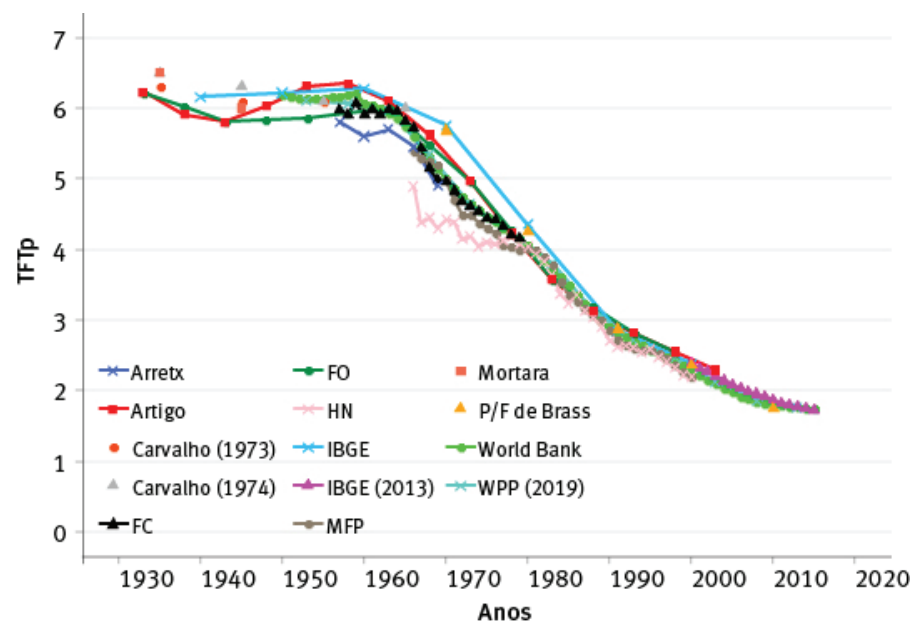

Fonte: Arretx (1983); Carvalho (1973, 1974); FO: Frias e Oliveira (1990, 1991); IBGE (1985, 2000); IBGE (2013); World Bank (2017); FC: Fernandez e Carvalho (1986); HN e MFP: Miranda-Ribeiro (2007); Mortara (1954, 1961); P/F de Brass: Carvalho, Quaresma e Silva (2018); WPP: United Nations (2019).

É notório que, após a década de 1970, as diferenças entre as estimativas diminuem sensivelmente, existindo uma convergência entre elas. Isso sugere uma boa aderência da técnica desenvolvida originalmente por Frias e Oliveira (1990) neste período. Por isso, pode-se levantar a hipótese de que as diferenças no início do horizonte temporal das TFT aqui trazidas dar-se-iam, primordialmente, por especificidades das técnicas utilizadas, uma vez que não se parte do pressuposto de que a estrutura da fecundidade era constante, como feito, por exemplo, por Carvalho $(1973,1974)$, em relação à maioria das regiões, ${ }^{10}$ mas apenas que ela variava lentamente.

\section{A estrutura da fecundidade por idade}

Após a análise dos níveis da fecundidade, faz-se necessária uma maior compreensão da variação das estruturas da função de fecundidade de período, ao longo do tempo. Mais uma vez, presou-se pela parcimônia na apresentação dos resultados. 0 Gráfico 4 apresenta a distribuição relativa das taxas específicas de fecundidade, em cinco momentos no tempo, para quatro regiões e explicitam o peso que o nível da fecundidade em cada uma das idades tem na TFT, facilitando a visualização dos dados na presença de diferentes níveis, no tempo.

Foram escolhidos anos que se entendem como importantes ao longo da transição, pois representam o início da série histórica da fecundidade (1930-1935), o começo da recuperação da década de 1940 (1940-1945), discutida nas páginas anteriores, o fim dessa recuperação (1955-1960), o início da queda sustentada da fecundidade (1960-1965) e, por fim, o término do horizonte temporal da série estimada (2000-2005). Também foram

\footnotetext{
$\overline{{ }^{10} \text { Carvalho }(1973,1974)}$ não adotou esse pressuposto em relação às regiões Extremo Sul e São Paulo.
} 
selecionadas algumas regiões: o Nordeste Central, que teria apresentado os maiores níveis de fecundidade até o início dos anos 1970; e São Paulo e Rio de Janeiro, que teriam sido as regiões precursoras da queda da fecundidade no país, no início do século XX.

No Gráfico 4, nota-se um contraste entre o Nordeste Central, por um lado, e o Rio de Janeiro e São Paulo, por outro, estando a média nacional mais próxima ao nível da primeira região. 0 Brasil como um todo teve uma baixa variação do peso relativos das TEF. As distribuições sugerem que a função de fecundidade de período tornou-se ligeiramente mais precoce, entre 1930 e 1945; isto é, um leve rejuvenescimento da função de fecundidade. Essa é uma característica de locais que experimentam uma lenta queda de fecundidade, já que o controle se inicia entre as mulheres de ordem de parturição mais elevada, consequentemente, aquelas mais velhas dentro do período reprodutivo.

GRÁFICO 4

Distribuição relativa das estimativas das taxas específicas de fecundidade, segundo grupos de idade Brasil e regiões selecionadas - 1930-2005
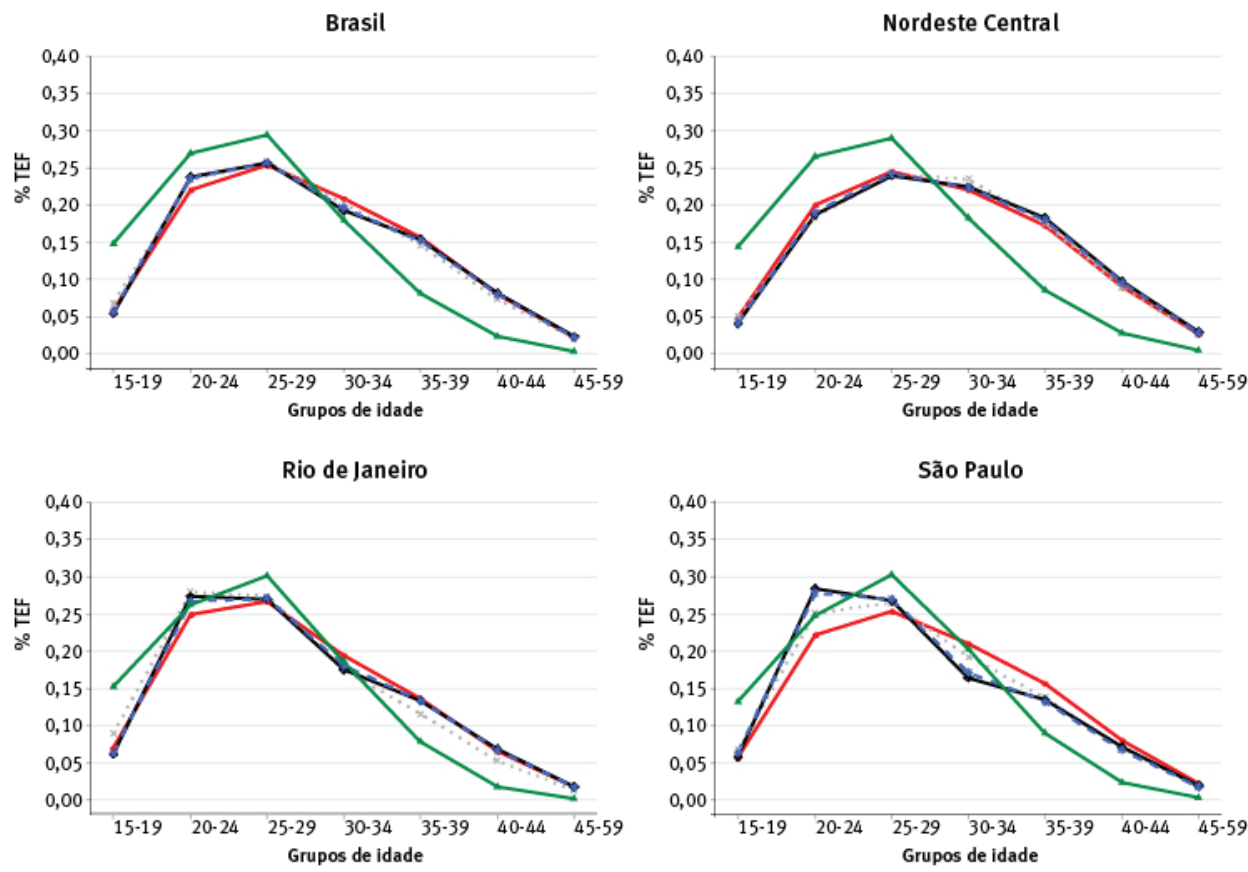

$-1930-1935 * 1940-1945 \quad-1955-1960 \quad * 1960-1965 \quad-2000-2005$

Fonte: Dados básicos dos Censos Demográficos de 1940, 1950, 1970 a 2010.

Nota: Estimativas obtidas a partir da aplicação da técnica proposta por Frias e Oliveira (1991), após breve ajuste na interpolação das taxas quinquenais.

A distribuição relativa da fecundidade de período de São Paulo conta uma história diferente sobre o padrão da fecundidade na região, em relação ao que foi discutido até aqui. 0 primeiro ponto é que, para os anos aqui selecionados, houve rejuvenescimento da fecundidade, pois as curvas foram se concentrando cada vez mais entre as mulheres mais 
jovens. Entre o fim dos anos 1950 e início da década de 1960, pouco teria mudado, atingindo o ápice do rejuvenescimento no início dos anos 2000. Aliás, esse rejuvenescimento da curva de fecundidade é comum a todas as regiões aqui descritas. ${ }^{11}$ Dada a alocação temporal imposta pela técnica, não se pode discorrer sobre os anos subsequentes, mas sabe-se que, já no Censo Demográfico de 2010, detectou-se um envelhecimento generalizado do padrão de fecundidade, não acompanhado por recuperação dos níveis de fecundidade. Isso já havia sido apontado por outros autores, inclusive destacando a seletividade de tal processo, por exemplo, entre grupos educacionais (MIRANDA-RIBEIRO; GARCIA, 2012, 2013; MIRANDA-RIBEIRO; GONÇALVES; RIOS-NETO, 2018).

Entre as três regiões aqui analisadas, além do total do Brasil, o Rio de Janeiro é aquela com a variação mais peculiar, quando se discute a função de fecundidade de período. É notória a menor variação relativa da estrutura da fecundidade em um intervalo de tempo considerável, entre 1930 e 2005 . Isso indica que o seu padrão de fecundidade já era, no início, mais jovem do que o de outras regiões do país, principalmente quando se comparam Rio de Janeiro e Nordeste Central. Teriam ocorrido um pequeno rejuvenescimento da estrutura, entre 1930 e 1945 , e um aumento do peso relativo da fecundidade das mulheres mais velhas, entre o segundo quinquênio da década de 1950 e o primeiro da de 1960 , retomando, praticamente, a mesma distribuição relativa de 1945 . Isso fica claro pela mudança das estruturas das curvas, tendo variado, principalmente, entre 1930 e 1945 . A recuperação que teria ocorrido, entre o início da década de 1940 e início dos anos 1960, teria sido predominante entre as mulheres mais velhas.

\section{O início da transição da fecundidade regional}

A pergunta central que norteou o trabalho é: quando e onde começou a transição da fecundidade no Brasil? Apesar de todas as estimativas até agora apresentadas, a pergunta em si ainda não foi respondida. Para tal, considerou-se que uma região iniciou o processo de transição da fecundidade quando a sua $\mathrm{TFT}^{\mathrm{P}}$ média quinquenal ${ }^{12}$ tenha registrado uma variação negativa de, pelo menos, $10 \%$, em um período de dez anos, seguindo um critério semelhante ao definido pelo European Fertility Project. Nele, o critério era, igualmente, de uma queda de $10 \%$ da fecundidade marital de período, em relação ao nível pré-transicional, para se considerar que a transição havia começado (COALE, 1986), mas sem indicação de um tempo máximo para tal declínio. Optou-se por impor um interregno de tempo máximo para o declínio de $10 \%$, tornando o critério mais restritivo. A impossibilidade de estimação do nível pré-transicional

\footnotetext{
${ }^{11} \mathrm{Em}$ uma perspectiva mais ampla da transição da fecundidade no Brasil, pode-se afirmar que o rejuvenescimento da curva de fecundidade fez parte da transição no país, especialmente entre 1991 e 2000 (BERQUÓ; CAVENAGHI, 2004).

12 Teoricamente, a melhor maneira para se discutir a transição da fecundidade seria a partir da análise da evolução da fecundidade de coortes sucessivas (FREJKA, 2017). No entanto, a imensa maioria dos trabalhos que procuram identificar o início da transição da fecundidade o faz a partir da evolução da fecundidade de período. Isso, de um lado, devido à disponibilidade dos dados e, de outro, porque, em princípio, teria que se esperar que as diversas coortes que iniciaram o processo chegassem ao término do período reprodutivo. No caso brasileiro, foi possível identificar a transição da fecundidade iniciada em várias regiões, antes do indicado pela análise da fecundidade de período, por meio das séries $\mathrm{P}_{i} / \mathrm{F}_{i}$ de Brass, baseadas nos dados do Censo Demográfico de 1970 (QUARESMA, 2019).
} 
para algumas regiões, como será discutido, foi uma limitação que levou à definição do conceito baseado, somente, na variação temporal. Este não seria o critério ideal, já que a diferença relativa negativa em relação ao nível pré-transicional, este geralmente constante ou oscilante, é justamente o marcador do início da transição da fecundidade.

No Gráfico 5 e na Tabela 1, apresentam-se as variações da TFTP média quinquenal, em intervalos decenais, em cada uma das regiões, além da média nacional, entre o início dos anos 1930 e 2000. Apesar de conterem a mesma informação, optou-se também pela apresentação da tabela, por ser o insumo principal para se responder à pergunta central do trabalho. A linha horizontal tracejada no Gráfico 5 refere-se a uma variação igual a zero, enquanto a linha horizontal preta marca o início da transição da fecundidade, ou seja, quando a variação da $\mathrm{TFT}^{\mathrm{P}}$ atinge $-10 \%$, conforme o critério aqui adotado. Com isso, é possível levantar novos indícios sobre o início da transição da fecundidade no país.

Entre 1930-1935 e 1940-1945, as maiores quedas acumuladas das TFT ${ }^{\mathrm{P}}$ médias quinquenais se deram em São Paulo (19,7\%) e no Rio de Janeiro (17,9\%), bem superiores ao critério adotado de $10 \%$. Como não há informação anterior a 1930, talvez nessas duas regiões a transição da fecundidade de período tenha se iniciado em décadas anteriores. 0 Extremo Sul também já estaria em processo de transição nos anos 1930, quando a TFT ${ }^{\mathrm{P}}$ teria caído, no período de dez anos, aproximadamente, $10 \%$. A região Leste também teria experimentado um declínio bem próximo daquele definido como indicador da transição em curso. No início da década de 1940, o Rio de Janeiro e o Extremo Sul teriam experimentado uma recuperação de fecundidade. Já em São Paulo, ela teria permanecido praticamente constante.

\section{GRÁFICO 5}

Variação decenal das taxas de fecundidade total de período quinquenais Brasil e regiões $-1930-2000$
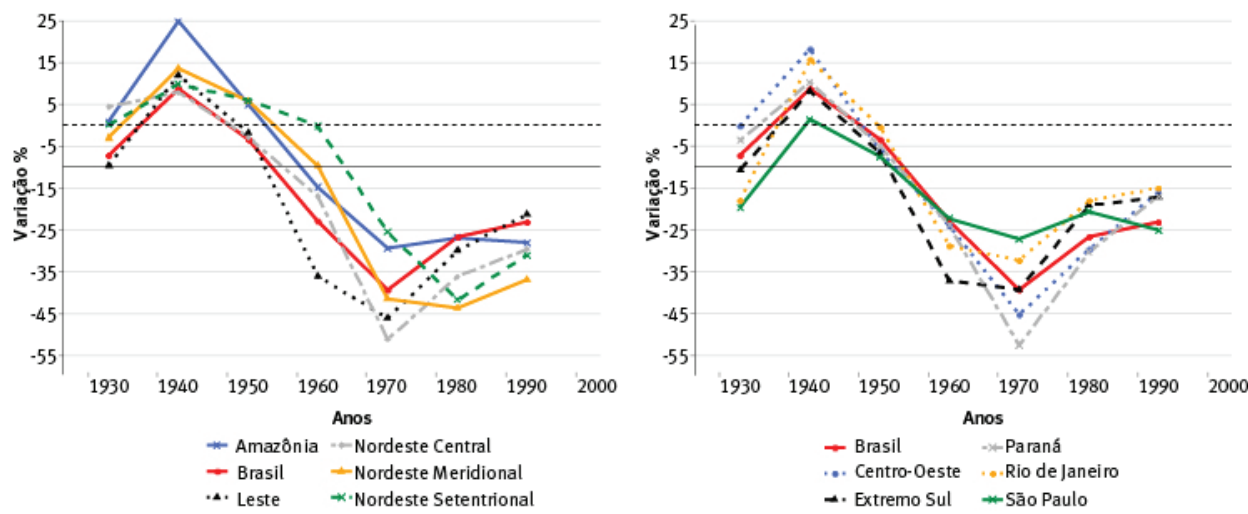

Fonte: Dados básicos dos Censos Demográficos de 1940, 1950, 1970 a 2010. 
TABELA 1

Variação decenal das TFTP quinquenais Brasil e regiões - 1930-2000

\begin{tabular}{|c|c|c|c|c|c|c|}
\hline \multicolumn{7}{|c|}{ Em porcentagem } \\
\hline Anos & Brasil & Amazônia & $\begin{array}{c}\text { Nordeste } \\
\text { Setentrional }\end{array}$ & $\begin{array}{c}\text { Nordeste } \\
\text { Central }\end{array}$ & $\begin{array}{c}\text { Nordeste } \\
\text { Meridional }\end{array}$ & Leste \\
\hline 1940-1945/1930-1935 & $-7,27$ & 0,84 & 0,19 & 4,39 & $-3,02$ & $-9,57$ \\
\hline 1950-1955/1940-1945 & 8,72 & 24,84 & 9,89 & 7,81 & 13,56 & 11,85 \\
\hline 1960-1965/1950-1955 & $-3,43$ & 4,94 & 5,98 & $-3,02$ & 5,80 & $-1,79$ \\
\hline 1970-1975/1960-1965 & $-22,75$ & $-14,79$ & $-0,20$ & $-16,91$ & $-9,66$ & $-36,13$ \\
\hline 1980-1985/1970-1975 & $-39,21$ & $-29,38$ & $-25,50$ & $-51,15$ & $-41,36$ & $-46,07$ \\
\hline 1990-1995/1980-1985 & $-26,51$ & $-26,81$ & $-41,63$ & $-36,20$ & $-43,55$ & $-29,96$ \\
\hline \multirow[t]{2}{*}{ 2000-2005/1990-1995 } & $-23,03$ & $-28,09$ & $-31,04$ & $-29,59$ & $-36,95$ & $-21,22$ \\
\hline & $\begin{array}{c}\text { Rio de } \\
\text { Janeiro }\end{array}$ & São Paulo & Paraná & Extremo Sul & Centro-Oeste & \\
\hline 1940-1945/1930-1935 & $-17,93$ & $-19,71$ & $-3,64$ & $-10,64$ & $-0,28$ & \\
\hline 1950-1955/1940-1945 & 15,65 & 1,37 & 10,21 & 8,20 & 18,13 & \\
\hline 1960-1965/1950-1955 & $-0,36$ & $-7,54$ & $-5,13$ & $-6,74$ & $-6,07$ & \\
\hline 1970-1975/1960-1965 & $-28,79$ & $-22,26$ & $-23,81$ & $-37,14$ & $-23,91$ & \\
\hline 1980-1985/1970-1975 & $-32,43$ & $-27,29$ & $-52,52$ & $-39,29$ & $-45,14$ & \\
\hline 1990-1995/1980-1985 & $-17,88$ & $-20,64$ & $-30,30$ & $-19,00$ & $-29,62$ & \\
\hline 2000-2005/1990-1995 & $-15,06$ & $-25,08$ & $-16,99$ & $-17,10$ & $-16,01$ & \\
\hline
\end{tabular}

Fonte: Dados básicos dos Censos Demográficos de 1940, 1950, 1970 a 2010. Nota: Variações calculadas a partir das TFTP apresentadas no Gráfico 2.

As demais regiões apresentaram tendências variadas, entre os inícios dos anos 1930 e 2000. No Nordeste Setentrional, por exemplo, a TFT ${ }^{\mathrm{P}}$ teria aumentado a taxas crescentes até o início da década de 1950, e a taxas decrescentes até o começo dos anos 1970, quando, finalmente, teria passado a variar negativamente, até o final do período analisado. A Amazônia teria apresentado tendência similar, mas com um crescimento mais acentuado, entre os primeiros quinquênios dos anos 1940 e 1950. Para as regiões Amazônia, Nordeste Central, Centro-Oeste, Leste, Paraná e, provavelmente, Nordeste Meridional, além do país como um todo, a transição teria começado entre o final dos anos 1960 e início da década de 1970. Tal inferência tem por base a comparação das variações de dois períodos, 19601965/1955-1960 e 1970-1975/1960-1965. Por último, o Nordeste Setentrional teria tido sua transição iniciada entre 1970-1975 e 1980-1985.

Da mesma forma que Coale (1986), o critério de $10 \%$, aqui utilizado, não impede que haja alguma recuperação da fecundidade de período, característica de algumas regiões no Brasil, como mencionado. Entretanto, passado o início dos anos 1960, observou-se um declínio sustentado da TFT $^{\mathrm{P}}$ do Brasil, enquanto média, e de praticamente todas as suas regiões.

Esta breve recuperação seria insuficiente para refutar o apontamento de que a transição da fecundidade teria começado, pelo menos, ainda nos anos 1930, no caso de parte do país. Nos países desenvolvidos, pioneiros no processo de transição da fecundidade, também observou-se recuperação da fecundidade após a década de 1940 (SÁNCHEZ-BARRICARTE, 2018; VAN BAVEL; REHER, 2013), sendo que, em parte deles, o aumento se deu ainda na 
década de 1930 (SÁNCHEZ-BARRICARTE, 2018). Este aumento esteve presente, por exemplo, na transição da fecundidade dos Estados Unidos, do Canadá, da Austrália, da Inglaterra, da Noruega e da França. Todos vivenciaram o baby boom após a Segunda Guerra Mundial.

As estimativas aqui apresentadas trazem indícios de que a transição da fecundidade regional teria se iniciado em São Paulo, no Rio de Janeiro e, também, no Extremo Sul, na perspectiva de período, pelo menos a partir dos anos 1930.

TABELA 2

Datação do início da transição da fecundidade de período, usando como critério a evolução das TFTP Brasil e regiões - 1930-2005

\begin{tabular}{lc}
\hline \multicolumn{1}{c}{ Região } & Datação \\
\hline Brasil & $1960-1965 / 1970-1975$ \\
Amazônia & $1960-1965 / 1970-1975$ \\
Nordeste Setentrional & $1960-1965 / 1970-1975$ \\
Nordeste Central & $1960-1965 / 1970-1975$ \\
Nordeste Meridional & $1960-1965 / 1970-1975$ \\
Leste & $1960-1965 / 1970-1975$ \\
Rio de Janeiro & $1930-1935 / 1940-1945$ \\
São Paulo & $1930-1935 / 1940-1945$ \\
Paraná & $1960-1965 / 1970-1975$ \\
Extremo Sul & $1930-1935 / 1940-1945$ \\
Centro-Oeste & $1960-1965 / 1970-1975$ \\
\hline
\end{tabular}

Fonte: Dados básicos dos Censos Demográficos de 1940, 1950, 1970 a 2010.

Nota: Nos casos do Rio de Janeiro, Extremo Sul e São Paulo, não se pôde afirmar o início da transição, por não se terem disponíveis estimativas da fecundidade de período para anos anteriores ao quinquênio 1930-1935.

\section{Considerações finais}

As escolhas metodológicas do trabalho se deram, em grande parte, pela limitação de como as informações estavam disponíveis nos censos e pela possibilidade de se estimarem os níveis de fecundidade a partir de poucas informações. No caso dos Censos Demográficos de 1940 e 1950, havia somente os dados tabulados pelo IBGE nos tomos referentes a esses censos.

Um primeiro problema para a aplicação da técnica é o impacto que a mortalidade poderia gerar nas estimativas. Como as informações dizem respeito às mulheres sobreviventes na data do censo, uma alta mortalidade materna, caso seletiva quanto à fecundidade, poderia subestimar os níveis de fecundidade. A não seletividade é uma condição, por exemplo, presente em outras técnicas aqui mencionadas, como o P/F de Brass e o método dos filhos próprios. Se houve seletividade, com maior mortalidade das mulheres com maior fecundidade, o começo da transição da fecundidade, provavelmente, iniciou-se em períodos anteriores aos aqui apontados.

Embora a transição da fecundidade de período esteja bem documentada pela literatura, com foco nos diferenciais entre as populações urbana e rural e na heterogeneidade inter e 
intrarregional, a constatação de que houve uma primeira fase da transição da fecundidade, em várias regiões do país, e de quando teria se iniciado permanece como uma lacuna dentro da literatura.

Apesar de claras indicações de queda em parte do Centro-Sul do país, mostradas pelos dados do Censo Demográfico de 1970, alguns trabalhos chegaram a atribuí-la não a uma verdadeira tendência, mas sim a diferenciais de qualidade dos dados entre as regiões (CARVALHO, 1974a, 1974b). Alguns autores trouxeram indícios de que a transição da fecundidade poderia já ter começado ainda nos anos 1940, em parte dos municípios brasileiros (POTTER et al., 2006, 2010), ou, em algumas regiões, até mesmo desde o início da década de 1930 (FRIAS; CARVALHO, 1992, 1994; FRIAS; OLIVEIRA, 1990, 1991; HORTA; CARVALHO; FRIAS, 2000; MERRICK, 1974; SAUNDERS, 1958). Há de se observar que os trabalhos de autores ou coautores brasileiros só foram publicados a partir da década de 1990.

Tendo em vista o que aqui se entendeu como divergência sobre quando o processo de transição da fecundidade teria começado, neste artigo, colocou-se em questão o início da transição. Procuraram-se indícios que permitissem uma aproximação da resposta à pergunta: quando e onde começou a transição da fecundidade no Brasil?

0 critério adotado para a definição do início da transição da fecundidade de período foi que a região precisaria experimentar, entre três quinquênios sucessivos, uma variação negativa de $10 \%$ da TFT $^{\mathrm{P}}$.

A partir disso, constatou-se que a transição teria se iniciado em São Paulo, no Rio de Janeiro e no Extremo Sul, no mínimo, a partir dos anos 1930. Talvez, a transição tenha começado antes, porém, não há dados para as décadas anteriores. A variação estimada no Leste $(-9,57 \%)$, muito próxima do limite adotado (-10\%), sugere que essa região possa ter iniciado a transição da fecundidade de período na década de 1930. As demais regiões do país teriam entrado no processo de transição da fecundidade, sem terem passado pela primeira fase, a partir da década de 1960, ou até mesmo início dos anos 1970, quando a fecundidade teria declinado sem interrupções em todas as áreas do país, de maneira sustentada e a altas taxas.

Uma importante limitação do exercício aqui realizado foi a impossibilidade de se estimar o nível da fecundidade pré-transicional para algumas regiões e, consequentemente, o início da transição da fecundidade em parte do Brasil (Rio de Janeiro, São Paulo e Extremo Sul). Apesar disso, entende-se que um importante passo na discussão é dado ao se afirmar que o processo já estaria em curso, pelo menos, desde meados da década de 1930.

Em paralelo, as informações disponíveis para a aplicação da técnica impuseram outro desafio aos autores: o tratamento da não resposta. Infelizmente, os tomos de 1940 e 1950 não trazem as não respostas, impossibilitando uma análise detalhada. Entretanto, caso a não resposta tenha sido incorporada à tabulação como zero filho, uma possível tendência de declínio aqui identificada estaria provavelmente subestimada, tendo o processo de queda iniciado, talvez, ainda antes de meados da década de 1930. 
Foram apontadas duas fases da transição da fecundidade no Brasil. A primeira, semeIhante à transição europeia, longa e lenta, limitada e concentrada ao Centro-Sul do país no Rio de Janeiro, São Paulo e no Extremo Sul. A segunda, rápida, como também se observou em inúmeros países em desenvolvimento na segunda metade do século passado, teria se dado a partir da década de 1960, em todas as demais partes do Brasil. As mesmas duas fases, para agregações regionais diferentes, foram mencionadas por Rios-Neto (2000).

Como síntese, enumeram-se algumas das limitações e contribuições deste trabalho. A principal limitação com a qual se lidou foi a ausência de dados, segundo os estados, para décadas anteriores a 1940, assim como a não disponibilidade dos microdados entre 1940 e 1960. A qualidade do dado é outro problema. A técnica proposta por Frias e Oliveira (1990, 1991) depende, fortemente, da qualidade da informação de filhos nascidos vivos. Caso a diferença de qualidade na captação da informação entre os censos seja substantiva, isso pode ter gerado uma subestimação da tendência de queda da fecundidade. Dessa forma, há a possibilidade de as conclusões serem conservadoras, podendo a transição ter-se iniciado anteriormente ao aqui datado. Ainda, partiu-se do pressuposto de não seletividade da mortalidade das mulheres, em relação à fecundidade, sendo as estimativas aqui apresentadas para as mulheres sobreviventes.

Apesar do caráter empírico do trabalho, entende-se que o artigo ajuda a levantar pontos para o debate, principalmente sobre a primeira fase da transição, além de destacar a intensidade do fenômeno. Acredita-se que a principal característica da demografia seja, justamente, a possibilidade e a capacidade de articular as estimativas com as diferentes abordagens teóricas, vindas de diversos campos, como a história, a sociologia, a economia e a antropologia, por exemplo. Por isso, é tão relevante que outros pesquisadores, caso concordem com a técnica de estimação, usem os resultados apresentados, para o melhor entendimento da dinâmica demográfica brasileira.

Por último, os perfis identificados da transição da fecundidade sugerem a existência anterior - por parte das gerações ou coortes captadas no enfoque transversal, nas medidas de período aqui utilizadas - de mudanças no comportamento reprodutivo. Esta hipótese comprova-se desenvolvendo uma análise de coorte com os dados utilizados neste artigo, haja vista que uma quantidade expressiva de coortes de mulheres captadas nesses dados iniciou e concluiu seu período reprodutivo. ${ }^{13}$

Outros autores contribuíram previamente com estimativas de fecundidade para pontos específicos no tempo (CARVALHO, 1973, 1974a, 1974b; IBGE, 1985, 2004; MORTARA, 1954, 1961), ou séries mais completas, mas, em sua maioria, contemplaram períodos mais recentes, após 1950, para os quais havia uma disponibilidade maior de dados e técnicas de estimação, além de facilidade de processamento (ARRETX, 1983; FERNANDEZ; CARVALHO,

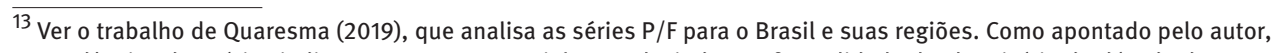
as tendências das séries indicam que as coortes vinham reduzindo sua fecundidade desde o início da década de 1930, com destaque para Rio de Janeiro, São Paulo e o Extremo Sul. Apesar de ser uma dimensão demográfica diferente, coorte e não período, em conjunto, as estimativas estariam contando a mesma história demográfica.
} 
1986; IBGE, 2013; MIRANDA-RIBEIRO, 2007; UNITED NATIONS, 2019; WORLD BANK, 2017). A exceção, talvez, sejam as estimativas de Frias e Oliveira $(1990,1991)$ e aquelas posteriores, que procuraram adicionar taxas de coorte (FRIAS; CARVALHO, 1992, 1994), ou ajustar as estimativas prévias de Frias e Oliveira (HORTA; CARVALHO; FRIAS, 2000).

A partir das estimativas apresentadas, pode-se afirmar que o processo de transição da fecundidade já estava em curso em parte do país, pelo menos, desde meados dos anos 1930. Entretanto, esta conclusão parte de uma definição estritamente relacionada às taxas de fecundidade. De acordo com a literatura, existem ao menos três pré-condições para que a transição da fecundidade comece: a redução do número de filhos tem que fazer parte da escolha racional da mulher; ela precisa ser vantajosa, inclusive, com baixo custo social; e métodos contraceptivos, assim como o conhecimento sobre como utilizá-los, devem estar disponíveis (COALE, 1973). Neste trabalho, nenhuma destas pré-condições foi analisada, mesmo porque inexistem informações a respeito. Por falta de dados, nada se pode afirmar em relação ao início do processo em São Paulo, Rio de Janeiro e Extremo Sul, mas fica evidente que o processo estava em andamento, já na década de 1930. Entende-se que as evidências apresentadas são importantes para nortear futuras pesquisas que busquem discutir, a partir de uma abordagem mais substantiva, o início supracitado. Vale lembrar que algumas práticas contraceptivas eram comuns no Rio de Janeiro, uma das regiões aqui mencionadas, já no final do século XIX (ROHDEN, 2003).

\section{Referências}

ABBASI-SHAVAZI, M. J.; MCDONALD, P.; HOSSEINI-CHAVOSHI, M. The fertility transition in Iran: revolution and reproduction. New York: Springer, 2009.

AHLBERG, J. H.; NILSON, E. N.; WALSH, J. H. Theory of splines and their applications. Academic Press, 1967.

ALVES, J. E. D. Transição da fecundidade e relações de gênero no Brasil. Tese (Doutorado) - Centro de Desenvolvimento e Planejamento Regional (Cedeplar), Universidade Federal de Minas Gerais (UFMG), Belo Horizonte, 1994.

ALVES, J. E. D. Questões demográficas: fecundidade e gênero. Rio de Janeiro: Escola Nacional de Ciências Estatísticas (Ence), IBGE, 2004a. (Textos para discussão).

ALVES, J. E. D. "O choque de civilizações" versus progressos civilizatórios. In: CAETANO, A. J.; ALVES, J. E. D.; CORRÊA, S. (org.). Dez anos do Cairo: tendências da fecundidade e direitos reprodutivos no Brasil. Campinas: Associação Brasileira de Estudos Populacionais (Abep), 2004b.

ARRETX, C. Levels and recent trends in fertility and mortality in Brazil. Washington, D.C., 1983.

BERQUÓ, E. S. Sobre a política de planejamento familiar no Brasil. Revista Brasileira de Estudos de População, v. 4, n. 1, p. 95-103, 1987.

BERQUÓ, E. S.; CAVENAGHI, S. M. Mapeamento sócio-econômico e demográfico dos regimes de fecundidade no Brasil e sua variação entre 1991 e 2000. In: ENCONTRO NACIONAL DE ESTUDOS POPULACIONAIS, 14. Anais [...]. Caxambu, MG: Abep, 2004.

BOOTH, $\mathrm{H}$. The estimation of fertility from incomplete cohort data by means of the transformed Gompertz model. London: University of London, 1980. 
BOOTH, H. Transforming gompertz's function for fertility analysis: the development of a standard for the relational gompertz function. Population Studies, v. 38, n. 3, p. 495-506, 1984.

BRASS, W. Methods for estimating fertility and mortality from limited and defective data. San Jose, Costa Rica, 1975.

BRASS, W. Demographic data analysis in less developed countries: 1946-1996. Population Studies, v. 50, n. 3, p. 451-467, 1996.

BRASS, W.; COALE, A. J. Methods of analysis and estimation. In: BRASS, W. et al. (ed.). The demography of tropical Africa. 1. ed. New Jersey: Princeton University Press, 1968. p. 88-139.

CARVALHO, J. A. M. de. Analysis of regional trends in fertility, mortality and migration in Brazil, 1940-1970. Ph.D. (Dissertation) - School of Economics and Political Science, London, 1973.

CARVALHO, J. A. M. de. Regional trends in fertility and mortality in Brazil. Population Studies, v. 28, n. 3, p. 401-421, 1974a.

CARVALHO, J. A. M. de. Tendências regionais de fecundidade e mortalidade no Brasil: Monografia. Belo Horizonte, MG, 1974b.

CARVALHO, J. A. M. de. Aplicabildiade da técnica de fecundidade de Brass quando a fecundidade está declinando ou quando a população não é fechada. In: ENCONTRO NACIONAL DE ESTUDOS POPULACIONAIS, 3. Anais [...]. Vitória, BA: Abep, 1982.

CARVALHO, J. A. M. de; BRITO, F. A demografia brasileira e o declínio da fecundidade no Brasil: contribuições, equívocos e silêncios. Revista Brasileira de Estudos de População, v. 22, n. 2, p. 351-369, 2005.

CARVALHO, J. A. M. de; HORTA, C. J.; WAJNMAN, S. Construindo uma medida do tempo médio despendido pelas coortes de mulheres com os cuidados de filhos pequenos. In: ENCONTRO NACIONAL DE ESTUDOS POPULACIONAIS. Anais [...]. Caxambu, MG: Abep, 2000.

CARVALHO, J. A. M. de; PAIVA, P. de T. A.; SAWYER, D. R. The recent sharp decline in fertility in Brazil: economic boom, social inequality and baby bust. Cidade do México: The Population Council, 1981. (Working Paper).

CARVALHO, J. A. M. de; QUARESMA, G.; SILVA, L. G. de C. E. Application of P/F Brass ratio method in the context of fast-paced adolescent fertility decline. Revista Brasileira de Estudos de População, v. 35, n. 1, 2018.

CARVALHO, J. A. M. de; WONG, L. L. R. La transición de la fecundidad en Brasil: causas y consecuencias. Notas de Población, n. 56, p. 107-141, 1992.

CASTANHEIRA, H. C.; KOHLER, H.-P. It is lower than you think it is: recent total fertility rates in Brazil and possibly other Latin American countries. University of Pennsylvania, 2015. (PSC Working Paper Series, 63).

CASTANHEIRA, H. C.; KOHLER, H.-P. It is lower than you think: recent total fertility rates in Brazil and possibly other Latin American countries. In: POPULATION ASSOCIATION OF AMERICA ANNUAL MEETING. Proceedings [...]. Washington, D.C.: Population Association of America, 2016.

CAVENAGHI, S. M.; ALVES, J. E. D. Qualidade das informações sobre fecundidade no Censo Demográfico de 2010. Revista Brasileira de Estudos de População, v. 33, n. 1, p. 189-205, 2016.

CAVENAGHI, S. M.; GOLDANI, A. M. Fecundidade e família: os tamanhos das famílias das mulheres e das crianças no Brasil. Revista Brasileira de Estudos de População, v. 10, n. 1, p. 107-124, 1993.

CHO, L.-J. Preliminary estimates of fertility for Korea Author. Population Index, v. 37, n. 1, p. 3-8, 1971. 
CHO, L.-J.; RETHERFORD, R. D.; CHOE, M. K. The own-children method of fertility estimation. 1. ed. Honolulu, Hawaii: University of Hawaii Press, 1986.

CLARK, G. A farewell to alms: a brief economic history of the world. 1. ed. Princeton: Princeton University Press, 2007.

COALE, A. J. The demographic transition reconsidered. In: INTERNATIONAL POPULATION CONFERENCE. Proceedings [...]. Liège, Belgium: International Union for the Scientific Study of Population - IUSSP, 1973.

COALE, A. J. The decline of fertility in Europe since the eighteenth century as a chapter in demographic history. In: COALE, A. J.; WATKINS, S. C. (ed.). The decline of fertility in Europe. 1. ed. Princeton: Princeton University Press, 1986.

COALE, A. J.; HOOVER, E. Population growth and economic development in low-income countries. 1. ed. Princeton: Princeton University Press, 1958.

DYSON, T. Population and development: the demographic transition. 1. ed. London: Zed Books Ltd., 2010.

FARIA, V. E. Políticas de governo e regulação da fecundidade: conseqüências não antecipadas e efeitos perversos. In: ANPOCS. Ciências sociais hoje. São Paulo: Anpocs/Vértice, 1989.

FEENEY, G. El metodo de hijos propios para estimar tasas de fecundidad por edad: notas praparadas para un seminariode analisis demografico y evaluacion the informaciones. Santiago, Chile: Centro Latinoamericano de Demografia - Celade, 1977.

FERNÁNDEZ, R. F.; CARVALHO, J. A. M. de. A evolução da fecundidade no Brasil, período 19571979. Aplicação da técnica dos filhos próprios para se estimar a fecundidade ano a ano. Revista Brasileira de Estudos de População, v. 3, n. 2, p. 67-86, 1986.

FREJKA, T. The fertility transition revisited: a cohort perspective. Comparative Population Studies, v. 42, p. 89-116, 2017.

FRIAS, L. A. de M.; CARVALHO, J. A. M. de. Uma avaliação de fecundidade no Brasil, ao início do século. Revista Brasileira de Estudos de População, v. 9, n. 2, p. 193-199, 1992.

FRIAS, L. A. de M.; CARVALHO, J. A. M. de. Fecundidade nas regiões brasileiras a partir de 1903: uma tentativa de reconstrução do passado através de gerações. In: ENCONTRO DE ESTUDOS POPULACIONAIS, 9. Anais [...]. Caxambu, MG: Abep, 1994.

FRIAS, L. A. de M.; OLIVEIRA, J. de C. Um modelo para estimar o nível e o padrão da fecundidade por idade com base em parturições observadas. Rio de Janeiro: IBGE, 1990. (Textos para Discussão, 37).

FRIAS, L. A. de M.; OLIVEIRA, J. de C. Níveis, tendências e diferenciais de fecundidade no Brasil a partir da década de 30. Revista Brasileira de Estudos de População, v. 8, n. 1, p. 72-111, 1991.

GENDELL, M. Fertility and development in Brazil. Demography, v. 4, n. 1, p. 143-157, 1967.

GRABILL, W. H.; CHO, L.-J. Methodology for the measurement of current fertility from population data on young children. Demography, v. 2, n. 1, p. 50-73, 1965.

HORTA, C. J.; CARVALHO, J. A. M.; FRIAS, L. A. de M. Recomposição da fecundidade por geração para Brasil e regiões: atualização e revisão. In: ENCONTRO NACIONAL DE ESTUDOS POPULACIONAIS, 12. Anais [...]. Caxambu, MG: Abep, 2000.

IBGE - Instituto Brasileiro de Geografia e Estatística. Estatísticas do século XX no Anuário Estatístico do Brasil. 1. ed. Rio de Janeiro: IBGE, 1985. 
IBGE - Instituto Brasileiro de Geografia e Estatística. Tendências demográficas: uma análise dos resultados do Censo Demográfico 2000. Rio de Janeiro: IBGE, 2004.

IBGE - Instituto Brasileiro de Geografia e Estatística. Projeções da população: Brasil e Unidades da Federação. Rio de Janeiro: IBGE, 2013. (Série Relatórios Metodológicos).

KIRK, D. Demographic transition theory. Population Studies, v. 50, p. 361-387, 1996.

KNODEL, J.; VAN DE WALLE, E. Lessons from the past: policy implications of historical fertility studies. Population and Development Review, v. 5, n. 2, p. 217-245, 1979.

LADIER-FOULADI, M. The fertility transition in Iran. Population: An English Selection, v. 9, p. 191-213, 1997.

MARQUES, D. H. F.; CARVALHO, J. A. M. de. Revisión de los niveles de fecundidad estimados mediante la técnica P/F de Brass en el Brasil y sus macrorregiones, 1980, 1991 y 2000. Notas de Población, v. 107, p. 193-206, 2018.

MARTINE, G. Brazil's fertility decline, 1965-95: a fresh look at key factors. Population and Development Review, v. 22, n. 1, p. 47-75, 1996.

MERRICK, T. W. Interregional differences in fertility in Brazil, 1950-1970. Demography, v. 11, n. 3, p. 423-440, 1974.

MIRANDA-RIBEIRO, A. Reconstrução de histórias de nascimentos a partir de dados censitários: aspectos teóricos e evidências empíricas. Tese (Doutorado) - Centro de Desenvolvimento e Planejamento Regional (Cedeplar), Universidade Federal de Minas Gerais (UFMG), Belo Horizonte, 2007.

MIRANDA-RIBEIRO, A. Minas Gerais, região Sudeste e Brasil: aplicação do método dos filhos próprios e a transição da fecundidade no período 1956-2000. In: SEMINÁRIO SOBRE A ECONOMIA MINEIRA, 12. Anais [...]. Diamantina,MG: Cedeplar/UFMG, 2006.

MIRANDA-RIBEIRO, A.; GARCIA, R. A. Transições da fecundidade no Brasil: uma análise à luz dos diferenciais por escolaridade. In: ENCONTRO NACIONAL DE ESTUDOS POPULACIONAIS, 18. Anais [...]. Águas de Lindóia, SP: Abep, 2012.

MIRANDA-RIBEIRO, A.; GARCIA, R. A. Transition or transitions? Analyzing the fertility decline in Brazil in the light of educational levels. Revista Latinoamericana de Población, v. 7, n. 13, p. 91-106, 2013.

MIRANDA-RIBEIRO, A.; GONÇALVES, G. Q.; RIOS-NETO, E. L. G. Postponement of births in Brazil: is time to think about recovery? In: POPULATION ASSOCIATION OF AMERICA ANUAL MEETING. Proceedings [...]. Denver, CO: PAA, 2018.

MIRÓ, C. A. Políticas de população na América Latina em meados de 1985: um panorama confuso. Revista Brasileira de Estudos de População, v. 4, n. 1, p. 87-94, 1987.

MORTARA, G. The development and structure of Brazil's population. Population Studies, v. 8, n. 2, p. 121-139, 1954.

MORTARA, G. A fecundidade das mulheres e a sobrevivência dos filhos no Brasil, segundo o censo de 1950. Revista Brasileira de Estatística, v. 17, n. 67, p. 177-186, 1956.

MORTARA, G. A fecundidade da mulher e a sobrevivência dos filhos no Brasil, segundo o Censo de 1950. In: IBGE (ed.). Contribuições para o estudo da demografia do Brasil. 1. ed. Rio de Janeiro: IBGE, 1961. p. 66-79.

MOULTRIE, T. A. The relational Gompertz model. In: MOULTRIE, T. et al. (ed.). Tools for demographic estimation. 1. ed. Paris: International Union for the Scientific Study of Population, 2013. p. 54-68. 
MUNDIGO, A. Os casos de China e Brasil. Revista Brasileira de Estudos de População, v. 4, n. 1, p. 77-86, 1987.

NOTESTEIN, F. Population: the long view. In: SCHULTZ, T. (ed.). Food for the world. Chicago, Illinois: University of Chicago Press, 1945. p. 36-57.

NOTESTEIN, F. Economic problems of population change. In: INTERNATIONAL CONFERENCE OF AGRICULTURAL ECONOMISTS, 8. Proceedings [...]. London: Oxford University Press, 1953.

OLIVEIRA, L. A. P. de; SILVA, N. L. P. da. Tendências da fecundidade nos primeiros anos da década e 80. In: ENCONTRO NACIONAL DE ESTUDOS POPULACIONAIS, 5. Anais [...]. Águas de São Pedro, SP: Abep, 1986.

OLIVEIRA, M. C.; BILAC, E. D.; MUSZKAT, M. Homens e anticoncepção: um estudo sobre duas gerações masculinas das “camadas médias" paulistas. In: ENCONTRO NACIONAL DE ESTUDOS POPULACIONAIS, 12. Anais [...]. Caxambu, MG: Abep, 2000.

PAIVA, P. de T. A. O processo de proletarização e a transição da fecundidade no Brasil. Revista Brasileira de Economia, v. 41, n. 4, p. 383-414, 1987.

PERPÉTUO, I.; WONG, L. L. R. Towards a replacement rate: programs and policies which affected the fertility course in Brazil. Papeles de Población, n. 47, p. 220-250, 2006.

POTTER, J. E. et al. Measuring the timing and pace of fertility decline in Brazil using a bayesian spatial estimation procedure. In: ENCONTRO NACIONAL DE ESTUDOS POPULACIONAIS, 15. Anais [...]. Caxambu, MG: Abep, 2006.

POTTER, J. E. et al. Mapping the timing, pace, and scale of the fertility transition in Brazil. Population and Development Review, v. 36, n. 2, p. 283-307, 2010.

POTTER, J. E.; SCHMERTMANN, C. P.; CAVENAGHI, S. M. Fertility and development: evidence from Brazil. Demography, v. 39, n. 4, p. 739-761, 2002.

QUARESMA, G. et al. Tendências da fecundidade no Brasil entre 1946 e 1960: uma tentativa de reconstituição a partir do método dos filhos próprios. In: ENCONTRO NACIONAL DE ESTUDOS POPULACIONAIS, 21. Anais [...]. Poços de Caldas, MG: Abep, 2018.

QUARESMA, G. Tendências regionais da transição da fecundidade brasileira corrente e de coorte ao longo do século XX. Tese (Doutorado) - Centro de Desenvolvimento e Planejamento Regional (Cedeplar), Universidade Federal de Minas Gerais (UFMG), Belo Horizonte, 2019.

RIOS-NETO, E. L. G. Passado, presente e futuro da fecundidade: uma visão de idade, período e coorte. Revista Brasileira de Estudos de População, v. 17, n. 1, p. 5-15, 2000.

RIOS-NETO, E. L. G. Questões emergentes na análise demográfica: o caso brasileiro. Revista Brasileira de Estudos de População, v. 22, n. 2, p. 371-408, 2005.

ROHDEN, F. A arte de enganar a natureza: contracepção, aborto e infanticídio no início do século XX. 1. ed. Rio de Janeiro: Editora Fiocruz, 2003.

ROSEN, B. C.; SIMMONS, A. B. Industrialization, family and fertility: a structural-psychological analysis of the Brazilian case. Demography, v. 8, n. 1, p. 49-69, 1971.

SACCO, N.; ANDREOZZI, L. Proyecciones y retroproyecciones probabilísticas de las tasas por edad (1895-2040). Revista Latinoamericana de Población, v. 11, n. 20, p. 79-104, 2017.

SACCO, N.; BORGES, G. ¿Converge la fecundidad en Brasil y Argentina? Un enfoque desde las desigualdades. Revista Brasileira de Estudos de População, v. 35, n. 1, p. 1-29, 2018.

SÁNCHEZ-BARRICARTE, J. J. Measuring and explaining the baby boom in the developed world in the mid-20th century. Demographic Research, v. 38, p. 1189-1240, 2018. 
SAUNDERS, J. V. D. Differential fertility in Brazil. 1. ed. Gainesville: University of Florida Press, 1958.

SCHMERTMANN, C. P. et al. Bayes plus Brass: estimating total fertility for many small areas from sparse census data. Population Studies, v. 67, n. 3, p. 255-273, 2013.

SIMÃO, A. B. et al. Comparando as idades à primeira relação sexual, à primeira união e ao nascimento do primeiro filho de duas coortes de mulheres brancas e negras em Belo Horizonte: evidências quantitativas. Revista Brasileira de Estudos de População, v. 23, n. 1, p. 151-166, 2006.

SIMÕES, C. C. DA S.; OLIVEIRA, L. A. P. de. Perfil estatístico de crianças e mães no Brasil: a situação da fecundidade; determinantes gerais e características da transição recente. 1. ed. Rio de Janeiro: IBGE, 1988.

TERÁN, M. M. Y. Evolución demográfica de México en el siglo XX. In: NADALIN, S. O.; MARCILIO, M. L.; BALHANA, A. P. (ed.). História e população: estudos sobre América Latina. São Paulo: Fundação Sistema Estadual de Análise de Dados, 1990. p. 81-87.

TUIRAN, R. et al. Fertility in Mexico: trends and forecast. New York, 2002.

UNITED NATIONS. Department of Economic and Social Affairs. Population Division. World population prospects: the 2019 revision. DVD Edition, 2019.

VAN BAVEL, J.; REHER, D.-S. The baby boom and its causes: what we know and what we need to know. Population and Development Review, v. 39, n. 2, p. 257-288, 2013.

VERONA, A. P.; POTTER, J. E. Fecundidade no Rio Grande do Sul entre 1946 e 1960: uma análise utilizando o método dos filhos próprios. In: ENCONTRO NACIONAL DE ESTUDOS POPULACIONAIS, 16. Anais [...]. Caxambu, MG: Abep, 2008.

WAJNMAN, S. Demografia das famílias e dos domicílios brasileiros. Tese (Professora Titular) Universidade Federal de Minas Gerais (UFMG), Belo Horizonte, 2012.

WONG, L. L. R. Fecundidade no Brasil (urbano e rural) - aplicação do Método dos Filhos Próprios ao Censo de 1970. Informe Demográfico, v. 1, n. 9, p. 53-98, 1983 a.

WONG, L. L. R. Níveis e tendências da fecundidade nas diversas regiões do Brasil - aplicação do Método dos Filhos Próprios ao Censo de 1970. Informe Demográfico 1, v. 1, n. 9, p. 99-140, 1983b.

WONG, L. L. R.; OLIVEIRA, J. de C. Níveis e diferenciais de fecundidade para o Brasil segundo os dados censitários de 1980 (notas preliminares). In: ENCONTRO NACIONAL DE ESTUDOS POPULACIONAIS, 4. Anais [...]. Águas de São Pedro, SP: Abep, 1984.

WORLD BANK. World development indicators, 2017. Disponível em: «http://worldpopulationreview. com/countries/s.

ZABA, B. Use of the relational Gompertz model in analysing fertility data collected in retrospective surveys. London: Center for Population Studies / London School of Hygiene \& Tropical Medicine, 1981.

ZARATE, A. O. Fertility in urban areas of Mexico: implications for the theory of the demographic transition. Demography, v. 4, n. 1, p. 363-373, 1967.

\section{Sobre os autores}

Guilherme Quaresma Gonçalves é doutor em Demografia pela Universidade Federal de Minas Gerais (UFMG). Coordenador de Gestão Hospitalar da Secretaria de Estado de Saúde de Minas Gerais (SES-MG). 
José Alberto Magno de Carvalho é doutor em Demografia pela Universidade de Londres, professor emérito da Universidade Federal de Minas Gerais (UFMG) e pesquisador do Centro de Desenvolvimento e Planejamento Regional (Cedeplar).

Laura Lídia Rodríguez Wong é doutora em Demografia pela London School of Hygiene and Tropical Medicine. Professora associada da Faculdade de Ciências Econômicas (Face), Departamento de Demografia, Universidade Federal de Minas Gerais (UFMG) e pesquisadora do Centro de Desenvolvimento e Planejamento Regional (Cedeplar).

Cássio Maldonado Turra é doutor em Demografia pela Universidade da Pensilvânia. Professor associado da Faculdade de Ciências Econômicas (Face), Departamento de Demografia, Universidade Federal de Minas Gerais (UFMG) e pesquisador do Centro de Desenvolvimento e Planejamento Regional (Cedeplar).

\section{Endereço para correspondência}

\section{Guilherme Quaresma Gonçalves}

Universidade Federal de Minas Gerais, Faculdade de Ciências Econômicas, Departamento de Demografia

Av. Pres. Antônio Carlos, 6627, Pampulha

31270-901 - Belo Horizonte-MG, Brasil

José Alberto Magno de Carvalho

Universidade Federal de Minas Gerais, Faculdade de Ciências Econômicas, Departamento de Demografia

Av. Pres. Antônio Carlos, 6627, Pampulha

31270-901 - Belo Horizonte-MG, Brasil

Laura Lídia Rodríguez Wong

Universidade Federal de Minas Gerais, Faculdade de Ciências Econômicas, Departamento de Demografia

Av. Pres. Antônio Carlos, 6627, Pampulha

31270-901 - Belo Horizonte-MG, Brasil

Cássio Maldonado Turra

Universidade Federal de Minas Gerais, Faculdade de Ciências Econômicas, Departamento de Demografia

Av. Pres. Antônio Carlos, 6627, Pampulha

31270-901 - Belo Horizonte-MG, Brasil.

\section{Abstract}

Fertility transition in Brazil across the $20^{\text {th }}$ century - a regional perspective

The essence of fertility transition is the shift from intensive reproduction, when many children are born but few survive, to a new pattern where births are fewer and planned. Some articles discussing fertility transition in Brazil indicate that this process began in the second half of the 1960s, characterizing the Brazilian transition as late and fast. Despite this consensus, the objective of this paper was to identify "when" and "where" fertility transition started in Brazil, reassessing regional fertility transition. We used the method proposed by Frias and Oliveira (1991) applied to Brazilian census data (1940, 1950 and 1970 to 2010) Results indicate that fertility transition had been underway since, at least the 1930s in some of Brazil's most important regions like Rio de Janeiro, São Paulo, and the far South. Because of this complex scenario, we argue 
that Brazil experienced two phases of fertility transition. The first one would have been long and slow, like the European fertility transition, pioneered by Rio de Janeiro, São Paulo, and the far South, whereas the second one was short and fast, in line with the fertility transition observed in countries where the process began later.

Keywords: Period fertility transition. Brazil. Regional fertility differentials.

\section{Resumen}

La transición de la fecundidad en Brasil durante el siglo XX. Una perspectiva regional

La esencia de la transición de la fecundidad es el cambio de un patrón de reproducción intensiva -cuando nacen muchos niños y pocos sobreviven- a otro en el cual la mayor parte de los nacimientos son planificados. Gran parte de la literatura sobre la transición de la fecundidad en Brasil indica que este proceso comenzó en la segunda mitad de la década del sesenta, lo que la caracateriza como tardía y rápida. A pesar de este aparente consenso, el objetivo de este trabajo es determinar cuándo y dónde comenzó esta transición, identificando este proceso desde el punto de vista regional. Se aplica el método de Frias y Oliveira, originalmente propuesto en 1991, a los datos de fecundidad reciente de los censos demográficos de Brasil de 1940, 1950 y 1970 a 2010. Los resultados indican que la transición de la fecundidad ya estaba en curso, en parte de Brasil, desde principios de la década del treinta en Río de Janeiro, en San Pablo y en el extremo sur del país. Como consecuencia de este escenario heterogéneo, habría dos fases de la transición: la primera, larga y lenta, similar al modelo europeo, cuyos precursores fueron Río de Janeiro, San Pablo y el extremo Sur; la segunda, corta y rápida, como la transición de los países rezagados en el proceso.

Palabras clave: Transición de la fecundidad reciente. Fecundidad regional. Brasil. 


\section{ANEXO 1}

\section{Equações do modelo Frias e Oliveia}

O primeiro cálculo para a aplicação da técnica de Frias e Oliveira é o do número de filhos tidos nascidos vivos até a data de referência da pesquisa. Considera-se que a função acumulada do número médio de filhos nascidos mortos, por idade da mãe, é descrita de acordo com o acúmulo do número médio de filhos mortos, por idade da mulher, resultando nas equações apresentadas a seguir (FRIAS; OLIVEIRA, 1991):

$s_{j}=\frac{F T_{j}-F S_{j}}{M j}$

$s_{i}=\sum_{j=1}^{i} s_{j}$

$F N M_{i}=M_{i} *\left(A_{i} * S_{i}^{k}-A_{i-1} * S_{i-1}^{k}\right)$

Onde:

$F T_{j}=$ filhos tidos por mães do grupo etário $j$, sendo $j$ igual a $1,2, \ldots, 7$.

$F S_{j}=$ filhos sobreviventes de mães do grupo etário $j$.

$M_{j}=$ mulheres do grupo etário $j$.

$s_{j}=$ número médio de filhos mortos de mulheres do grupo etário $j$.

$S_{i}=$ número médio acumulado de filhos mortos de mulheres do grupo etário $j$.

$F N M_{i}=$ filhos tidos nascidos mortos de mães do grupo etário $i$, sendo $i$ igual a $1,2, \ldots, 7$. $A_{i}, k=$ coeficientes $A_{i}$ e parâmetro $k$ das equações para estimar os filhos tidos nascidos mortos por grupos quinquenais de idade das mulheres. Os valores encontram-se no Anexo 2 (Tabela A1).

A partir das parturições médias das mulheres de 15 a 19, 20 a 24, 25 a 29 e 30 a 34 anos, estimam-se, primeiro, as fecundidades acumuladas. Para tal, utiliza-se o conjunto de equações a seguir ${ }^{14}$ (FRIAS; OLIVEIRA, 1990, 1991).

$$
\begin{aligned}
& F(20)=A_{0} * P(17,5)^{A_{1}} * P(22,5)^{A_{2}} * P(27,5)^{A_{3}} * P(32,5)^{A_{4}} \\
& F(25)=B_{0} * P(22,5)^{B_{1}} * P(27,5)^{B_{2}} * P(32,5)^{B_{3}} \\
& F(30)=C_{0} * P(22,5)^{C_{1}} * P(27,5)^{C_{2}} * P(32,5)^{C_{3}} \\
& F(35)=D_{0} * P(22,5)^{D_{1}} * P(27,5)^{D_{2}} * P(32,5)^{D_{3}} \\
& F(40)=E_{0} * P(17,5)^{E_{1}} * P(27,5)^{E_{2}} * P(32,5)^{E_{3}} \\
& F(45)=G_{0} * F(30)^{G_{1}} * F(35)^{G_{2}} * F(40)^{G_{3}} \\
& F(50)=H_{0} * F(40)^{H_{1}} * F(45)^{H_{2}}
\end{aligned}
$$

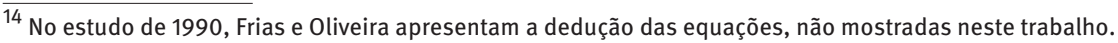


Onde:

$A_{i}, B_{i}, C_{i}, D_{i}, E_{i}, G_{i}, H_{i}=$ Parâmetros das equações dos modelos de fecundidade acumulada. Os parâmetros encontram-se no Anexo 2 (Tabela A2).

As equações 2.1 a 2.7 não partem da parturição, mas sim da fecundidade acumulada estimada para os demais grupos etários. Isso garante que não se pressuponha uma fecundidade relativamente estável para os últimos 45 anos, mas sim para os últimos 20 (FRIAS; OLIVEIRA, 1991). Isso é essencial, pois, de modo geral, o início do controle da fecundidade se dá em parturições de ordens mais elevadas e dentre as mulheres mais velhas, condição essa que seria claramente violada. Se a fecundidade não é constante nos últimos 20 anos, ter-se-ia uma subestimação do nível da fecundidade acumulada até a idade $a$, ao se desacumular a parturição a partir das equações 2.1 até 2.7. Entretanto, como o controle se inicia dentre as mulheres mais velhas, em que as TEFs são menores, no início da transição esta subestimação será menor quanto menos acelerado for o ritmo de declínio da fecundidade. Mesmo em um ritmo acelerado de declínio, caso do Brasil após a década de 1970, a diferença entre as TFTs estimadas ao se aplicar a técnica proposta por Frias e Oliveira $(1990,1991)$ e outras técnicas, com pressupostos distintos, foi muito pequena, ponto este já discutido ao se analisar o Gráfico 3. Ainda, as mulheres de parturição mais elevada tendem a apresentar maior erro de memória, ${ }^{15}$ crescente com a idade, o que diminuiria a qualidade das estimativas.

Por fim, desacumulam-se os valores de $F(a)$, obtendo-se, assim, as taxas específicas de fecundidade. As equações apresentadas a seguir são utilizadas para tal (FRIAS; OLIVEIRA, 1990, 1991). A tabela com os parâmetros também está no Anexo 2 (Tabela A3).

$f(15-19)=F(20) *\left[a_{0}+a_{1} * F(50)\right]$

$f(20-24)=F(25) *\left[b_{0}+b_{1} * F(50)\right]+F(20) *\left[b_{2} * F(50)+b_{3}\right]$

$f(25-29)=F(30) *\left[c_{0}+c_{1} * F(50)\right]+F(25) *\left[c_{2} * F(50)+c_{3}\right]$

$f(30-34)=\frac{F(35) *\left[d_{0}+d_{1} * F(50)\right]+F(30) *\left[d_{2} * F(50)+d_{3}\right]}{1+d_{4} * F(35)+d_{5} * F(30)}$

$f(35-39)=\frac{F(40) *\left[e_{0}+e_{1} * F(50)\right]+F(35) *\left[e_{2} * F(50)+e_{3}\right]}{1+e_{4} * F(40)+e_{5} * F(35)}$

$f(40-44)=\frac{F(45) *\left[g_{0}+g_{1} * F(50)\right]+F(40) *\left[g_{2} * F(50)+g_{3}\right]}{1+g_{4} * F(45)+g_{5} * F(40)}$

$f(45-49)=\frac{F(50) *\left[h_{0}+h_{1} * F(50)\right]+F(45) *\left[h_{2} * F(50)+h_{3}\right]}{1+h_{4} * F(50)+h_{5} * F(45)}$

Onde:

$f(15-19)$ a $f(45-49)=$ taxas específicas de fecundidade;

$a_{i}, b_{i}, c_{i}, d_{i}, e_{i}, g_{i}, h_{i}=$ coeficientes das equações para estimar as taxas específicas de fecundidade por grupos de idade.

\footnotetext{
$\overline{15}$ Essa limitação é discutida por outros trabalhos, como na técnica da razão P/F (BRASS; COALE, 1968).
} 


\section{ANEXO 2}

\section{Tabelas com os coeficientes para a aplicação da técnica}

As Tabelas A2 e A3 trazem os coeficientes utilizados nas equações supracitadas, para a aplicação da técnica proposta por Frias e Oliveira $(1990,1991)$. Para a estimação dos coeficientes, os autores utilizaram as informações dos Censos Demográficos de 1940 a 1980, como descrito em Frias e Oliveira (1990). Foram excluídos da análise os estados do Norte, Centro-Oeste e Distrito Federal, restando 144 observações. ${ }^{16}$

Os coeficientes foram obtidos a partir de uma série de estimações de mínimos quadrados ordinários. Primeiro, os autores definiram a forma funcional que melhor descrevia a relação entre a fecundidade acumulada até a idade $a$ e as parturições médias observadas nos censos (equações 2.1 a 2.7 do Anexo 1). Em seguida, essa relação foi linearizada e foram estimados os coeficientes da Tabela A2. Processo similar foi realizado para a Tabela A3.

\section{TABELA A1}

Coeficientes $A_{i}$ e parâmetros $k$ das equações para estimar os filhos tidos nascidos mortos por grupos quinquenais de idade das mulheres

Fonte: Frias e Oliveira (1990).

\begin{tabular}{cc}
\hline$i$ & $A_{i}$ \\
\hline 1 & 0,1219156510 \\
2 & 0,1370351947 \\
3 & 0,1507705101 \\
4 & 0,1634522358 \\
5 & 0,1752967022 \\
6 & 0,1864547046 \\
7 & 0,1970363731 \\
$k$ & 0,86668444 \\
\hline
\end{tabular}

TABELA A2

Valores dos parâmetros das equações modelos de fecundidade acumulada

\begin{tabular}{cccccccc}
\hline $\boldsymbol{i}$ & $\boldsymbol{F ( 2 0 )}$ & $F(25)$ & $F(30)$ & $F(35)$ & $F(40)$ & $F(45)$ & \multicolumn{2}{c}{$F(50)$} \\
& $A_{i}$ & $B_{i}$ & $C_{i}$ & $D_{i}$ & $E_{i}$ & $G_{i}$ & $H_{i}$ \\
\hline 0 & 1,200118 & 0,895876 & 1,012988 & 0,984019 & 0,868603 & 0,998407 & 0,994680 \\
1 & 0,301590 & 0,144403 & $-0,018386$ & 0,028261 & $-0,025018$ & 0,140871 & $-0,204015$ \\
2 & 1,250309 & 1,256802 & 0,494253 & $-0,428986$ & $-0,710893$ & $-0,762433$ & 1,211073 \\
3 & $-0,800978$ & $-0,356139$ & 0,517650 & 1,410370 & 1,800768 & 1,631598 & - \\
4 & 0,220274 & - & - & - & - & - & - \\
\hline
\end{tabular}

Fonte: Frias e Oliveira (1990).

\footnotetext{
${ }^{16}$ Para uma maior compreensão da derivação para a estimação dos parâmetros, ler: FRIAS, L. A. de M.; OLIVEIRA, J. de C. Um modelo para estimar o nível e o padrão da fecundidade por idade com base em parturições observadas. Rio de Janeiro: IBGE, 1990. (Textos para Discussão, 37).

FRIAS, L. A. de M.; OLIVEIRA, J. de C. Níveis, tendências e diferenciais de fecundidade no Brasil a partir da década de 30. Revista Brasileira de Estudos de População, v. 8, n. 1, p. 72-111, 1991.
} 
TABELA A3

Valores dos coeficientes das equações para estimar as taxas específicas de fecundidade por grupos de idade

\begin{tabular}{|c|c|c|c|c|c|c|c|}
\hline$i$ & $\begin{array}{c}f(17,5) \\
a_{i}\end{array}$ & $\begin{array}{c}f(22,5) \\
b_{i}\end{array}$ & $\begin{array}{c}f(27,5) \\
c_{i}\end{array}$ & $\begin{array}{c}f(32,5) \\
d_{i}\end{array}$ & $\begin{array}{c}f(37,5) \\
e_{i}\end{array}$ & $\begin{array}{c}f(42,5) \\
g_{i}\end{array}$ & $\begin{array}{c}f(47,5) \\
h_{i}\end{array}$ \\
\hline 0 & 0,204207 & 0,259045 & 0,207653 & 0,167995 & 0,166491 & 0,182392 & 0,199712 \\
\hline 1 & $-0,006589$ & $-0,009918$ & $-0,000780$ & $-0,000333$ & $-0,000894$ & $-0,002541$ & $-0,008107$ \\
\hline 2 & - & 0,007858 & 0,000739 & 0,000340 & 0,000892 & 0,002548 & 0,008128 \\
\hline 3 & - & $-0,205244$ & $-0,196565$ & $-0,171871$ & $-0,166074$ & $-0,182851$ & $-0,200213$ \\
\hline 4 & - & - & - & $-0,158297$ & $-0,155667$ & $-0,259493$ & $-1,525749$ \\
\hline 5 & - & - & - & 0,161950 & 0,155277 & 0,260145 & 1,529572 \\
\hline
\end{tabular}

Fonte: Frias e Oliveira (1990). 